\title{
An amphioxus orthologue of the estrogen receptor that does not bind estradiol: Insights into estrogen receptor evolution Mathilde Paris ${ }^{1}$, Katarina Pettersson ${ }^{2}$, Michael Schubert ${ }^{1}$, Stephanie Bertrand ${ }^{3}$, Ingemar Pongratz ${ }^{2}$, Hector Escriva $^{3}$ and Vincent Laudet*1
}

Address: ${ }^{1}$ Institut de Génomique Fonctionnelle de Lyon, Molecular Zoology team, Université de Lyon, Ecole Normale Supérieure de Lyon, Université Lyon 1, CNRS, INRA, Institut Fédératif 128 Biosciences Gerland Lyon Sud, France, ${ }^{2}$ Karolinska Institutet, Department of Biosciences and Nutrition, S-141 57 Huddinge, Sweden and ${ }^{3}$ CNRS, UMR 7628, Modèles en Biologie Cellulaire et Evolutive, Observatoire océanographique, F-66651, Banyuls/mer, France

Email: Mathilde Paris - mathilde.paris@ens-lyon.fr; Katarina Pettersson - kape@biosci.ki.se; Michael Schubert - michael.schubert@ens-lyon.fr; Stephanie Bertrand - stephanie.bertrand@obs-banyuls.fr; Ingemar Pongratz - ingemar.pongratz@biosci.ki.se; Hector Escriva - hector.escriva@obs-banyuls.fr; Vincent Laudet* - vlaudet@ens-lyon.fr

* Corresponding author

Published: 25 July 2008

BMC Evolutionary Biology 2008, 8:219 doi:10.1 I86/147|-2।48-8-219
Received: 3 January 2008

Accepted: 25 July 2008

This article is available from: http://www.biomedcentral.com//47/-2/48/8/219

(c) 2008 Paris et al; licensee BioMed Central Ltd.

This is an Open Access article distributed under the terms of the Creative Commons Attribution License (http://creativecommons.org/licenses/by/2.0), which permits unrestricted use, distribution, and reproduction in any medium, provided the original work is properly cited.

\begin{abstract}
Background: The origin of nuclear receptors (NRs) and the question whether the ancestral NR was a liganded or an unliganded transcription factor has been recently debated. To obtain insight into the evolution of the ligand binding ability of estrogen receptors (ER), we comparatively characterized the ER from the protochordate amphioxus (Branchiostoma floridae), and the ER from lamprey (Petromyzon marinus), a basal vertebrate.

Results: Extensive phylogenetic studies as well as signature analysis allowed us to confirm that the amphioxus ER (amphiER) and the lamprey ER (lampER) belong to the ER group. LampER behaves as a "classical" vertebrate ER, as it binds to specific DNA Estrogen Responsive Elements (EREs), and is activated by estradiol $\left(E_{2}\right)$, the classical ER natural ligand. In contrast, we found that although amphiER binds EREs, it is unable to bind $E_{2}$ and to activate transcription in response to $E_{2}$. Among the 7 natural and synthetic ER ligands tested as well as a large repertoire of I 4 cholesterol derivatives, only Bisphenol A (an endocrine disruptor with estrogenic activity) bound to amphiER, suggesting that a ligand binding pocket exists within the receptor. Parsimony analysis considering all available ER sequences suggest that the ancestral ER was not able to bind $E_{2}$ and that this ability evolved specifically in the vertebrate lineage. This result does not support a previous analysis based on ancestral sequence reconstruction that proposed the ancestral steroid receptor to bind estradiol. We show that biased taxonomic sampling can alter the calculation of ancestral sequence and that the previous result might stem from a high proportion of vertebrate ERs in the dataset used to compute the ancestral sequence.

Conclusion: Taken together, our results highlight the importance of comparative experimental approaches vs ancestral reconstructions for the evolutionary study of endocrine systems: comparative analysis of extant ERs suggests that the ancestral ER did not bind estradiol and that it gained the ability to be regulated by estradiol specifically in the vertebrate lineage, before lamprey split.
\end{abstract}




\section{Background}

Hormone signaling is a very important feature in metazoans, allowing communication between cells or organs within the organism. Two components of these signaling systems are of particular importance, the hormone and its receptor. The nuclear hormone receptor (NR) superfamily includes ligand dependent transcription factors that play a central role in various physiological processes as diverse as reproduction, development, and control of homeostasis $[1,2]$. They share a common structural organization and exhibit a highly conserved DNA binding domain (DBD) and a moderately conserved ligand-binding domain (LBD). Some members of this superfamily are liganded receptors ( 24 among the 48 genes encoding NRs in the human genome) but many lack identified ligand and are therefore called "orphan" [3]. Some orphan receptors are 'true' orphans in the sense that they do not possess a bona fide ligand-binding pocket (LBP), like the members of the NR4 subfamily (for instance, NURR1, DHR38 or NGFI-B. For review, see [4]), and are regulated by other mechanisms [4]. Alternatively, the crystal structures of several orphan receptors such as HNF4 were found to have a phospholipid constitutively bound to a large ligand binding pocket $[5,6]$. The functional and evolutionary implications of these constitutive ligands remain discussed. Other orphan nuclear receptors have a ligand binding pocket and thus have the potential to bind compounds. It is still not known whether those receptors have natural ligands, still to be discovered. Undoubtedly, the existence of such orphan receptors with physiological or developmental activities constitutes both a major challenge for understanding nuclear receptor evolution and a potential opportunity for pharmacology [1].

The existence of orphan and liganded members in the NR family raises the question of the evolution regarding their ligand binding ability. Whether the ancestral NR was liganded or orphan and more generally how NR ligand binding ability evolved has been recently debated [7-14]. In general, it is still unclear if there is a correlation between the evolution of the hormone repertoire and NRs. Moreover the mechanisms underlying this coevolution are of particular interest $[7,12,15-19]$.

Among the scenarios of NR evolution that have been proposed, one suggests that the ancestral NR was a ligandindependent transcription factor which acquired the ability to be regulated by ligands several times during evolution [7,18-20]. This hypothesis was based on the observation that compounds of similar chemical nature bind to divergent NRs and on the contrary compounds of very different nature bind to closely related receptors. For instance, orphan receptors are found in all families of NRs, and steroid receptors are not monophyletic but are located in two different subfamilies within the NR super- family: the ecdysteroid as well as the sex steroid receptors. Interestingly, the evolution of sex steroid hormone receptors has also been used as an argument for an alternative hypothesis, the ligand exploitation model [8,11] (for an alternative view, see $[21,22])$. Phylogenetic trees show that sex steroid hormone receptors are grouped with ERRs as the NR3 subfamily, following the official nomenclature [23]. They contain receptors that bind estradiol (ERs), that form the NR3A group as well as mineralocorticoids (MRs), glucocorticoids (GRs), progesterone (PRs), and androgen (ARs) that form the NR3C group. All known ligands in this subfamily can be seen as variations around the archetypical sterol skeleton. Consequently, Thornton et al. suggested in the ligand exploitation model that the ancestral steroid receptor was a high affinity estradiol receptor $[8,11]$ and the other steroid receptors that originated later on, experienced, following gene duplication, shifts in their binding affinities to eventually bind to their extant ligand. The model in fact suggests that the newly duplicated receptors (here NR3C) exploit as ligands chemical species that serve as intermediary compounds in the "ancestral ligand" synthesis pathway (here the estradiol synthesis pathway) [8]. According to this view, orphan receptors, like ERRs, secondarily lost the ability to have their activity regulated by a ligand and became orphan. Interestingly, within the NR3 family, two receptor subfamilies, ERRs and ERs, appear to be ancient since they are found in a wide variety of metazoans including deuterostomes and protostomes, whereas, up to now, MRs, GRs, PRs and ARs have been found only in vertebrates. The only non-vertebrate ERs that have been described so far were from mollusks and were shown to be unable to bind estradiol $[11,12,24-26]$. Since the ligand exploitation model implies an ancestral estradiol-binding ER and since all liganded ER found so far come from vertebrates, and to improve taxonomic sampling, the ER orthologues from the basal vertebrate lamprey and the invertebrate chordate amphioxus were characterized here. Indeed, lamprey and amphioxus are located at key positions in the chordate phylum [27-30]. Moreover, amphioxus (Brachiostoma floridae) is much less derived than urochordates in its morphology as well as in its genome organization [30]. Indeed, amphioxus and vertebrates share a similar general body plan whereas urochordate morphology is more derived. For instance, during metamorphosis of some urochordates, the tadpole-like larva transforms into an adult that looks so different that it was first considered as a mollusk [31]. Moreover the urochordate genome is fast evolving [27], with for instance the loss of the clustering of the hox genes [32]. There is no ER in the sequenced genome of Ciona intestinalis [33] or in the sea urchin [34], one ER was previously cloned in lamprey [8], only one ER was found in the amphioxus genome [35]. These reasons make lamprey and amphioxus excellent models to study the evolution of estrogen signaling pathway at the origin 
of vertebrates. In this study, we cloned the unique ER from amphioxus (amphiER) and characterized it, as well as the previously cloned but uncharacterized lamprey ER (lampER). AmphiER is an orphan receptor, showing no affinity to the estrogen hormone estradiol, when in contrast, the lamprey ER behaves as a "classical" vertebrate ER. As no ER from invertebrates studied so far binds estradiol, we propose that the ancestral ER (and the ancestral steroid receptor) was not a receptor for estradiol and gained later on during evolution the ability to bind the hormone.

\section{Results}

\section{Cloning of the ER from amphioxus (amphiER)}

Using degenerate primers designed to match motifs in the most conserved part of vertebrate ERs in the DNA binding domain, a single gene fragment from total RNA of an adult Branchiostoma floridae was amplified, cloned and sequenced. Rapid amplification of cDNA ends (RACE) was utilized to obtain the full-length cDNA. From this sequence, a new set of specific primers were designed and used to amplify the full length open reading frame of this gene. The obtained cDNA [GenBank: ACF16007] is 2118 bp long and encodes a 705 aa long putative protein (Figure 1) that harbors the classical features of an ER with the 5 main functional domains (Figure 2A), among which a highly conserved DNA binding domain (DBD) and a less conserved ligand binding domain (LBD). The DBD shares an $82 \%$ sequence identity with the human ER $\alpha$ one (83\% with human ER $\beta$ ) and much less with the other NR3 receptors $(<62 \%)$. The same pattern is observed for the LBD, although this domain is less conserved since it exhibits only $34 \%$ amino acid identity with human ER $\alpha$ (35\% for human ER $\beta$ ) and about $20 \%$ with other steroid receptors (Figure 2A). The three other domains, namely the $\mathrm{A} / \mathrm{B}$ region in the $\mathrm{N}$-terminal part, the hinge between DBD and LBD, and the short C-terminal end of the protein, are more divergent, which is a general pattern for NRs [2] (Figure 2A). The recent release of the amphioxus genome confirmed the presence of a single ER gene [35]. In contrast the previously described lamprey ER is more similar to the human ER $\alpha$ with its DBD sharing a 93\% sequence identity ( $93 \%$ for human ER $\beta$ ) and its LBD sharing 55\% sequence identity (56\% for human ER $\beta$ ) [8].

\section{Phylogenetic analysis of ERs}

The orthology relationships of the amphioxus and lamprey ER sequences were studied in a phylogenetic analysis of the NR3 family using an exhaustive dataset comprising 69 members of the NR3 subfamily as well as sequences of RXRs as an outgroup. The dataset included the 6 currently known mollusk ER sequences (from Nucella lapillus, Crassostrea gigas, Marisa cornuarietis, Thais clavigera, Octopus vulgaris, Aplysia californica), as well as the 2 NR3 sequences previously known from amphioxus (1 ERR [GenBank: AAU88062] and 1 NR3C [JGI: 201600], retrieved from a previous work [36] or from the complete genome sequence [35]). In the resulting phylogenetic tree, the sequence of lamprey ER branches within the ER clade with a high bootstrap support $(95 \%)$, at the expected position before the split of vertebrate ER $\alpha$ and ER $\beta$ (Figure $2 \mathrm{~B}$, and for a tree presenting all sequences, see Additional file 1A), as previously shown [8]. The sequence of amphiER branches within the ERs and is located at the base of the vertebrate estrogen receptor group, before the split of $\mathrm{ER} \alpha$ and ER $\beta$ but after the split of the mollusk ERs (bootstrap value of $81 \%$, Figure 2B). However its precise position within the ER group is poorly supported (bootstrap value of $42 \%)$.

Such low bootstrap supports reveal either the weakness of the phylogenetic signal contained in ER proteins, or the presence of two incompatible signals in the data, one supporting the observed position of amphiER within ERs, and the other supporting another position. Whereas the weakness of the signal is not testable, the long branch leading to amphiER in the tree suggests that sites that have undergone a large number of substitutions may account for one of the two signals. Such sites may be saturated to the point that phylogenetic methods are not able to correctly recover their evolution, a situation leading to the long branch attraction artifact [37]. It is therefore important to correctly characterize sites that support the ER position of amphiER: if only fast-evolving sites support this hypothesis, it is probably due to long branch attraction, and an alternative branching should be favored. Alternatively, if slowly-evolving sites support this position, one can confidently identify amphiER as a bona fide ER. To characterize sites with respect to their evolutionary rates and the amphiER position they favor, both site likelihoods and site evolutionary rates were computed for all possible positions of amphiER.

First, AmphiER was pruned from the tree shown in Figure $2 \mathrm{~B}$, and then re-grafted in all 149 remaining branches. This yielded 149 topologies, for which site likelihoods and site evolutionary rates could be computed using PhyML-aLRT. This allowed us to obtain an evolutionary rate per site averaged over all possible positions of amphiER, and therefore independent from the precise position of amphiER in the tree. Additionally, as likelihoods were computed for each of the 149 positions, these positions could be compared according to the Approximately Unbiased test (AU test, implemented in Consel [38]). Out of all the 149 resulting trees, 26 could not be distinguished with the AU test and had a likelihood significantly better than all the other ones (p-value $>0,05$ ). Of these 26 topologies, all but three place amphiER within the ER clade ("ER" trees). The remaining topologies ("alter-ER" trees) place amphiER either at the base of the NR3C clade (comprising the ARs, PRs, MRs and GRs), within the NR3C or at the 


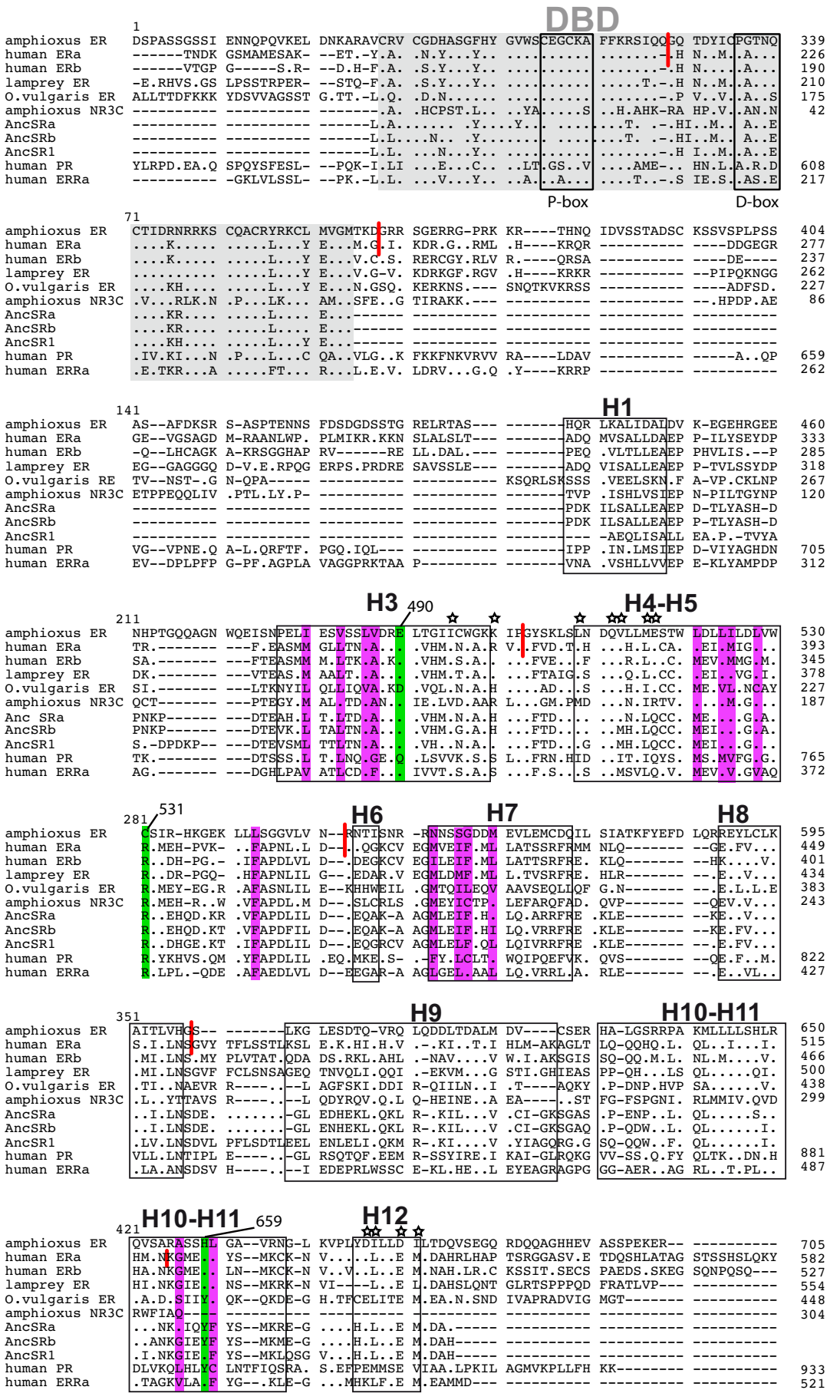

Figure I

Sequence alignment of several ERs including the amphioxus ER and the lamprey ER, as well as ancestral steroid receptors. The DBD is highlighted with light grey. The 12 helices from the LBD are indicated, based on the known 3D structure of human $E R \alpha$ [49]. Amino acids from human $E R \alpha$ making direct hydrogen bonds with $E_{2}$ are indicated in green. Amino acids making hydrophobic bonds with $E_{2}$ are highlighted in purple. Amino acids known to be involved in co-activator interaction have been indicated with a star on top of each site [55]. The more divergent $A / B$ domain as well as the $F$ domain have been omitted from the alignment. However, the numbering of the sites along the alignment starts at the beginning of each protein. The exon-intron limits of amphiER and humanER $\alpha$ have been indicated with small red strokes. The sequences of Anc$\mathrm{SRa}$ and AncSRb have been inferred in this study. The sequence of AncSRI was retrieved from a previous analysis [II]. 
A

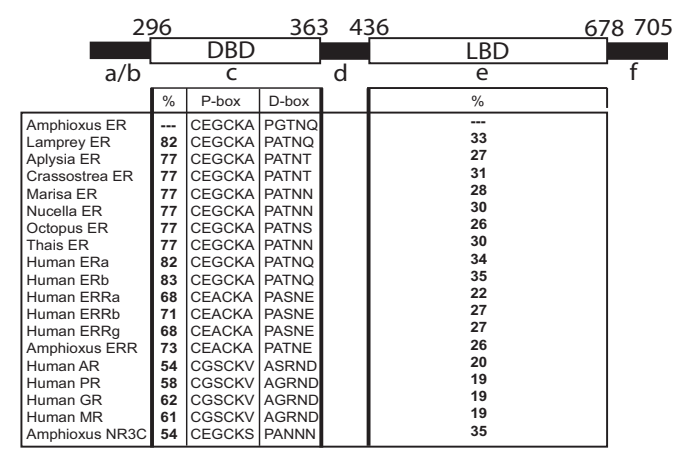

B

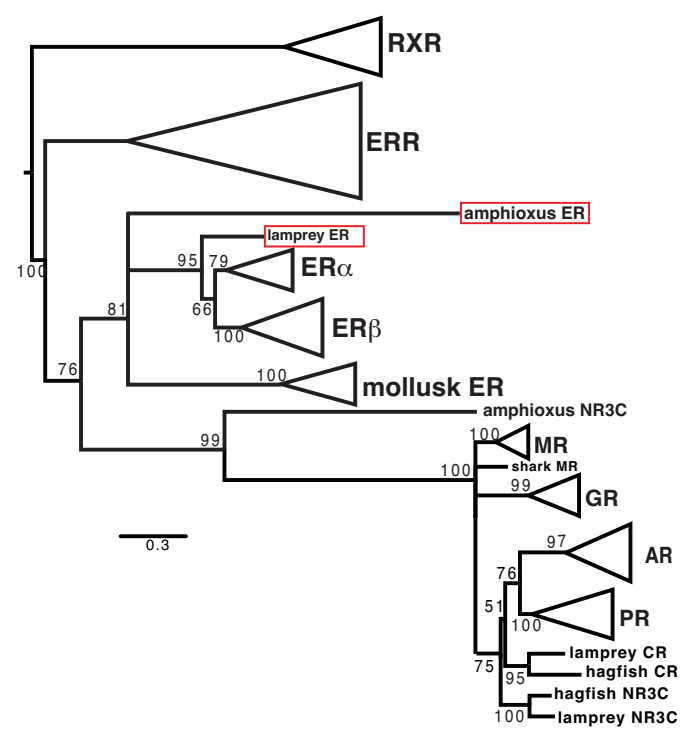

C

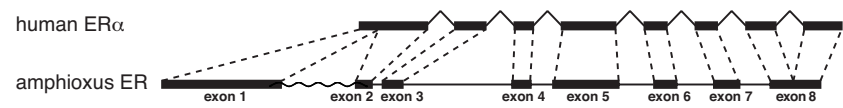

\section{Figure 2}

There is a single ER in amphioxus. (A) Schematic representation of the different domains of amphiER. Percent identity of the amphioxus ER with other sequences from the NR3 subfamily in the DNA- and ligand-binding domains is indicated. Amino acid sequence of the highly conserved $\mathrm{P}$-box and D-box in the DBD are shown. (B) Maximum likelihood $(\mathrm{ML})$ tree obtained from the analysis of the amino acid sequences of the DBD and the LBD of a wide range of NR3 under a JTT $+\gamma+i$ model. Bootstrap percentages obtained after I,000 ML replicates are shown above selected branches. Scale bar indicates number of changes per site. The tree was rooted by selected RXR sequences. (C) The exonintron structure of amphiER is conserved with that of human $E R \alpha$, except two minor differences: the first human exon corresponds to the first two amphioxus exons and the last two human exons correspond to the last amphioxus exon.

base of (ER, NR3C) (Figure 3A). Because site evolutionary rates had been computed, sites having a higher likelihood for the "alter-ER" trees could be compared with sites favoring the "ER" topologies with respect to their evolutionary rates. Interestingly, the sites pleading for the "alter-ER" trees evolve significantly faster than the sites pleading for the "ER" trees (mean evolutionary rates of 1.20 and 0.90 , $\mathrm{p}$-value $<10^{-5}$ with a Wilcoxon-test or $\mathrm{p}<0.001$ with a an unpaired t-test). This suggests that the "alter-ER" signal in the alignment is probably due to long branch attraction to the NR3C subtree, which might also be at the origin of the low bootstrap support (42\%) for the position of amphiER. Conversely, this suggests that amphiER should be considered as an ER, as the signal at the origin of this position does not seem to be artifactual.

An additional test can be run to further confirm this hypothesis, and consists in reestimating the phylogeny using only slowly-evolving sites. For that purpose, the distribution of expected relative evolutionary rates across sites of the alignment was plotted, as found by phymlaLRT $[39,40]$ (Figure 3B). Fastest-evolving sites were removed from the dataset based on three different rate thresholds $(2.5,2$ or 1.5 , Figure $3 \mathrm{~B}$ and $3 \mathrm{C})$, and trees were reconstructed based on the alignments containing only the remaining slowly-evolving sites. These operations did not impact the monophyly of ERs (Figure 3C) or the statistical support. This shows that the clustering of amphiER with vertebrate ERs does not come from saturated sites, which argues against long branch attraction being at the origin of this position [41]. Accordingly, complementary phylogenetic analyses with different methods (bayesian, Neighbor-joining, parsimony) gave similar results (see Additional file 1). From these studies we conclude that amphiER does indeed belong to the ER subfamily, which is confirmed by the general conservation of the exon-intron structure of amphiER with human ER $\alpha$, especially at two exon-intron splice sites in the DBD and in the LBD after helix 3 (Figure 2C and short red strokes in Figure 1) [42].

\section{Chordate ERs, including amphioxus ER and lamprey ER, are able to bind estrogen specific response elements (ERE)} To test whether the lamprey ER and the amphioxus ER are able to bind DNA on specific estrogen response elements (EREs), electrophoresis mobility shift assays were performed using a radiolabeled consensus ERE sequence (see Additional file 2). These experiments show that, like vertebrate ERs, amphiER and lampER are able to bind DNA specifically on a consensus ERE. This binding is specific, since a 100-fold excess of non-specific DNA was not able to compete for binding, whereas a 100 -fold excess of cold ERE completely suppressed it (see Additional file 2, compare lanes 15 and 17, as well as lanes 19 and 21). ERs contain two major conserved signatures in the DBD, the Pbox (CEGCKA), responsible for the binding specificity to response elements, and the D-box, also involved in the 


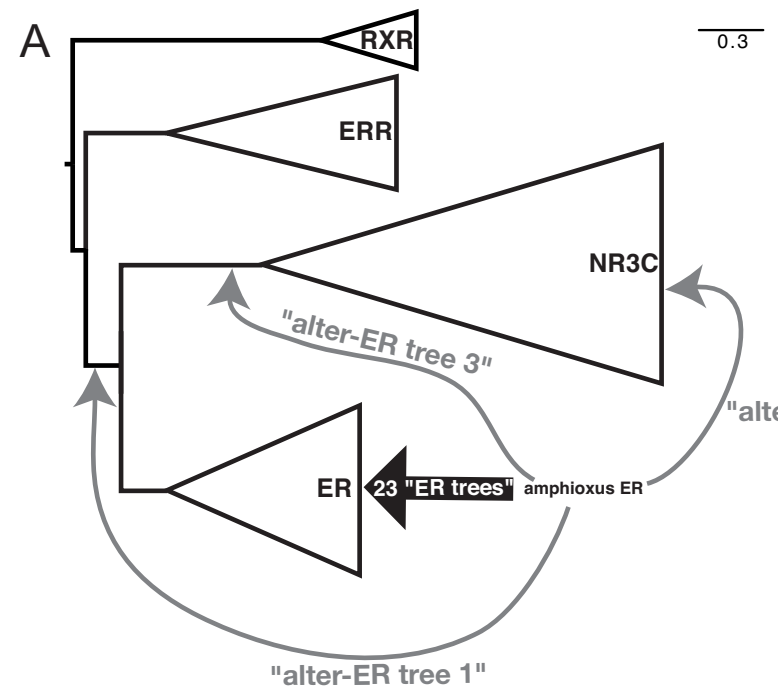

B

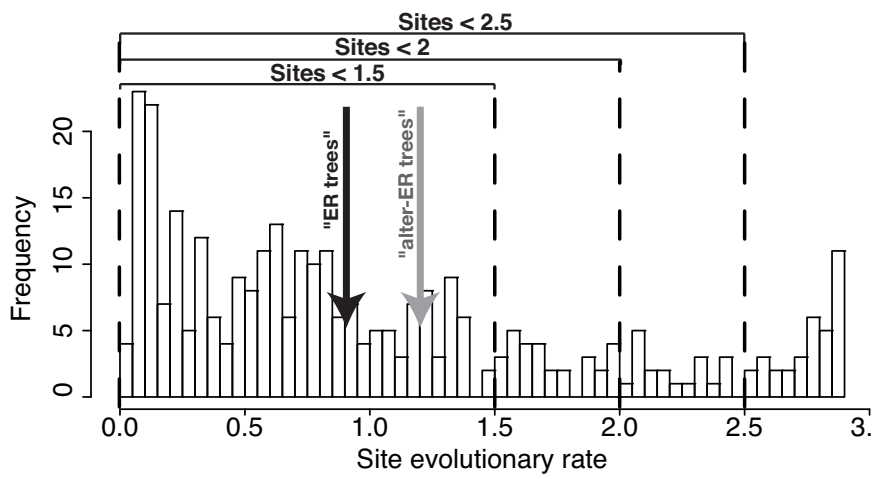

C

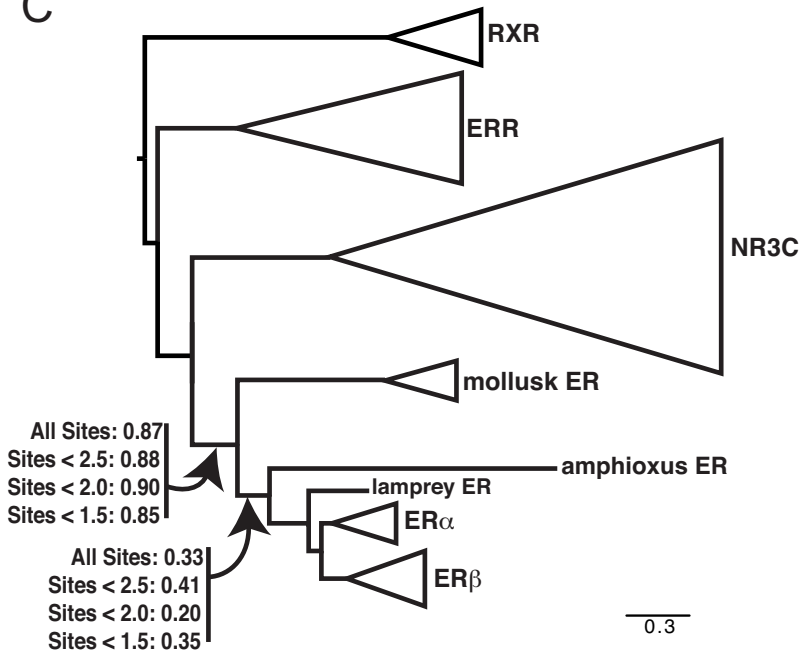

Figure 3

Phylogenetic analysis of amphiER. (A) Summary of the 26 best placements of amphiER within a phylogenetic tree comprised of 69 NR3 and 8 RXR sequences. 23/26 topologies ("ER-tree") place amphiER within the ER clade, the 3 remaining topologies ("alter-ER tree") place amphiER either at the base of (ER, NR3C) or within the NR3C family (close to an AR) or at the base of the NR3 family. The mean evolutionary rate of the sites supporting one of the 23 "ER-tree" topologies $(0,9)$ or for the "alter-ER tree" topologies $(I, 2)$ are indicated in (B). (B) Distribution of the site relative evolutionary rates. Rates were estimated using an 8 class discretized gamma distribution. The vertical dotted lines correspond to different tentative threshold $(2.5,2,1.5)$, above which sites have been discarded due to their high evolutionary rate, before reestimating the phylogeny of the consecutive alignment. (C) Estimation of the minimum of Chi2-based and SH-like supports, available in the aLRT-PHYML software, for the branches defining the monophyly of ERs as well as the position of amphiER. 4 trees were inferred using an alignment on which the fastest evolving sites were removed (no site removed, 34, 53 and 82 sites removed out of 323, with a mean evolutionary rate threshold above $2.5,2.0$ and 1.5 , respectively).

DNA binding specificity of the ER dimers (Figure 2A). The P-box is highly conserved in all known ERs, including amphiER and lamprey ER and is different from other NR3 members. AmphiER and lamprey ER also have a well conserved D-box, amphiER D-box containing just a few conservative mutations, (e.g. a mutation of an alanine in glycine, Figure 2A). Since the three characterized mollusk ERs (from A. californica, O. vulgaris and Thais clavigera $[11,12,24])$ also bind EREs and since the P-box and D-box are well conserved in all known ERs, including those from mollusks, ERE binding appears to be a feature specific to all ERs.

\section{Lamprey $E R$, but not amphioxus $E R$, is able to induce transactivation of a reporter gene in response to estradiol stimulation}

The transactivation ability of lamprey ER and amphiER was then compared with that of human ER $\alpha$. AmphiER failed to induce transcription of a reporter construct containing a consensus ERE in front of a minimal promoter 
in transfected mammalian cells after stimulation by the natural vertebrate ER ligand, estradiol $\left(\mathrm{E}_{2}\right)$ as well as a wide variety of other vertebrate ER ligands (the natural agonist $3 \beta$-androstenediol [43], and the phytoestrogens resveratrol [44] and enterolactone [45]) (Figure 4A and $4 \mathrm{~B})$. In order to improve the detection sensitivity, was also tested the transactivation capacity of amphiER in response to $\mathrm{E}_{2}$ as a construct containing only the LBD fused to the GAL4 DNA-binding domain. In this case again, no activation was detected (Figure 4C). In agreement with this result, no recruitment of the coactivator SRC1 (an homologue of which is present in the amphioxus genome, see
Discussion) was detected in mammalian two-hybrid assay (Figure 4D). However lampER is activated by $\mathrm{E}_{2}$, with an intensity comparable to humanER $\alpha$ (Figure 4C), which suggests that the lamprey ER is a high affinity $\mathrm{E}_{2}$-dependant transcription factor.

Since amphiER is able to bind DNA but is unable to activate transcription of a reporter gene, the dominant negative capacity of the amphioxus protein was tested. A dosedependent decrease in the reporter gene activity was clearly visible in 2 different cell lines when increasing amounts of the amphiER plasmid were added together
A consensus ERE
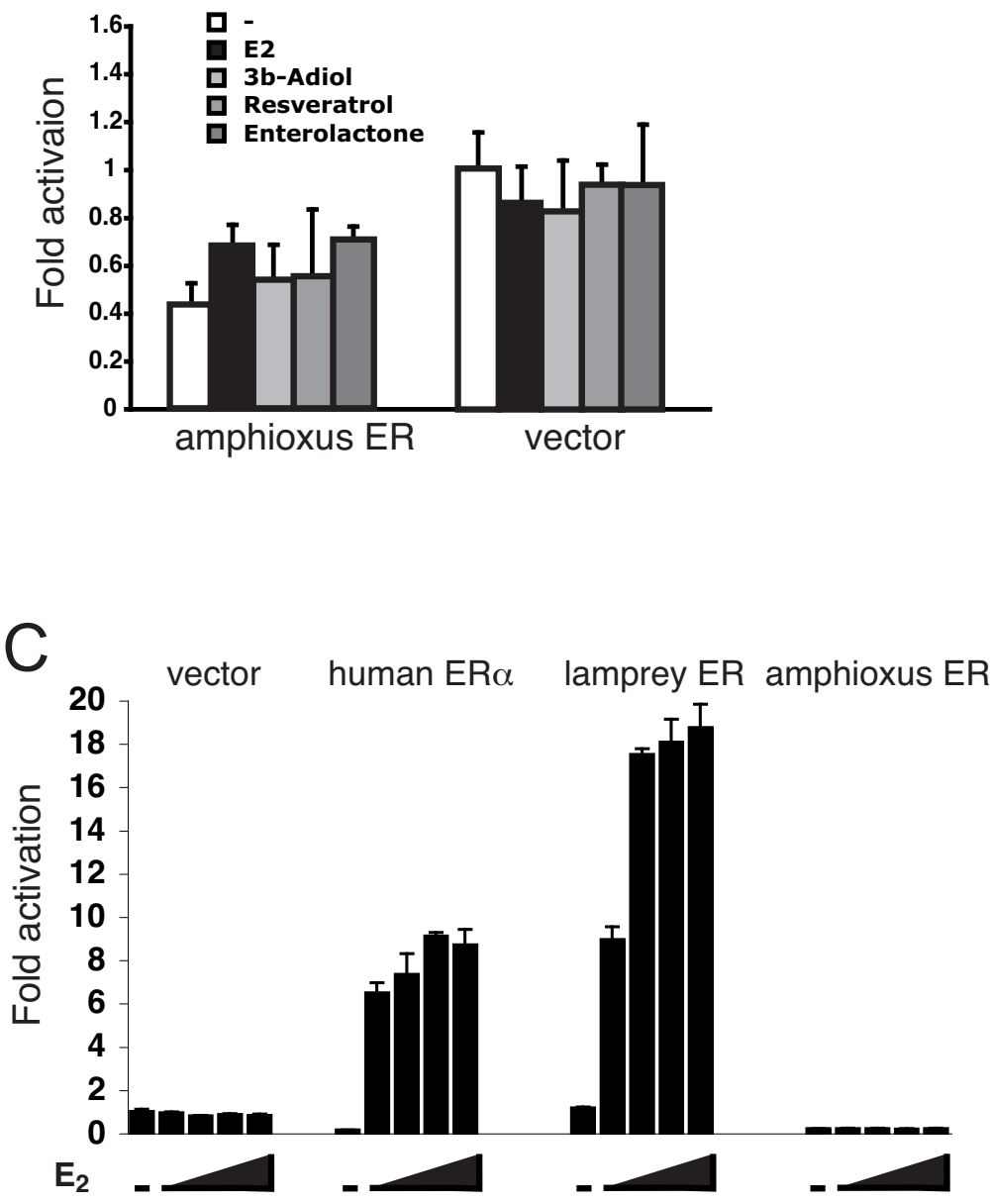
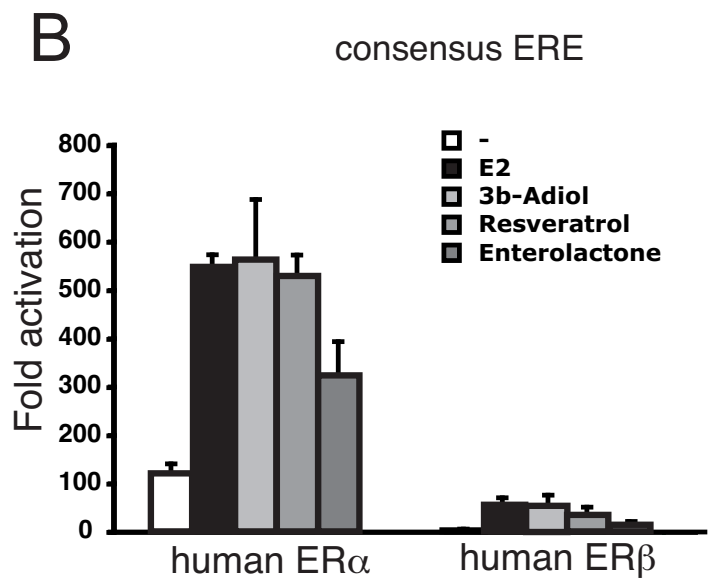

\section{Figure 4}

LampER is activated by $E_{\mathbf{2}}$ whereas amphiER is not activated by ER agonists. The pSG5 constructs containing either amphiER (A), human ER $\alpha$ or human $\operatorname{ER} \beta(B)$, were tested in transfected Cos 7 cells for their ability to activate the co-transfected cognate ERE-luc reporter plasmid after $E_{2}$ stimulation ( I0-6M). (C) GAL4-LBD constructs from several chordate ERs were tested in transfectec 293 cells for their ability to activate a $(17 \mathrm{~m}) 5 \mathrm{x}-\mathrm{G}$-luc reporter plasmid in the presence of increasing doses of $E_{2}\left(10^{-9} \mathrm{M}\right.$ to $\left.10^{-6} \mathrm{M}\right)$. (D) Mammalian two-hybrid SRCI recruitment assay. The GAL4-amphiER-LBD chimera was used with the coactivator SRCI fused to the strong activation domain VPI 6 to transfect 293 cells in the presence of increasing doses of $\mathrm{E}_{2}$ (10-9 M to $\left.10^{-6} \mathrm{M}\right)$. 
with constant amounts of human ER $\alpha$ or ER $\beta$ in transient transfection experiments. This decrease was observed both with synthetic consensus EREs (Figures 5A and 5B. See also Additional file 3) and with the natural ERE present in the classical ER pS2 target gene (Figure 5C). Apparently, amphiER is able to compete with human ER $\alpha$ or ER $\beta$ for binding to the ERE sites present in the reporter constructs, and in doing so, prevents ER $\alpha$ and ER $\beta$ from inducing transcription, which results in a decrease in reporter gene activity. Thus, in contrast to Aplysia, Octopus or Thais ER $[11,12,24]$, amphiER does not display constitutive transcriptional activity under our experimental conditions and rather exhibits an inhibitory effect (Figure 4). This clearly shows that the absence of transcriptional activity observed here is not an artifact linked to a poor expression of the construct but rather reflects the inability of amphiER to activate transcription in mammalian cells.

LampER is an estradiol receptor whereas amphiER is not able to bind ER ligands except the synthetic compound Bisphenol A

In order to confirm that lamprey ER is an $E_{2}$ receptor and to better understand the molecular basis behind the inability of the amphiER to become transcriptionally activated by estradiol stimulation, $\mathrm{E}_{2}$ binding by lamprey ER and amphiER was tested in vitro. For that purpose, limited proteolysis assay allows to assess whether addition of different putative ligands can induce a conformational change in amphiER [13]. Using this method the ligand induced conformational change of the LBD is revealed by the alteration of the receptor sensitivity toward proteolytic digestion by trypsin. As expected, $\mathrm{E}_{2}$ was able to protect human ER $\alpha$ from proteolysis (Figure 6A). Interestingly lamprey ER was also protected from proteolysis by $\mathrm{E}_{2}$ even at the lowest concentration tested (Figure 6A), thus confirming the results of the transactivation assays that the lamprey ER is a high affinity $\mathrm{E}_{2}$ receptor. In contrast no protection of amphiER by estradiol was observed, even at very high ligand concentrations $\left(10^{-3} \mathrm{M}\right)$ (Figure 6A). Since estradiol does not protect amphiER from proteolysis, several other classical ER ligands were tested, such as the synthetic ER agonists diethylstilbestrol [46], 4hydroxy-tamoxifene [46] or bisphenol A (BPA) [47], the natural agonist $3 \beta$-androstenediol [43], the phytoestrogen enterolactone [45] or the synthetic ER antagonist ICI182780 [46]. All compounds were able to bind to human ER $\alpha$ (Figure 6B to 6G) as expected, whereas none but BPA was able to bind to amphiER (Figure 6G). However, BPA did not induce transactivation by amphiER in mammalian cells reporter assay, and did not induce recruitment of the coactivator SRC1 either (see Additional file 4).

In order to rule out the possibility that amphiER is activated by a compound related to $E_{2}$, a large panel of 14 other steroids and cholesterol derivatives were tested for
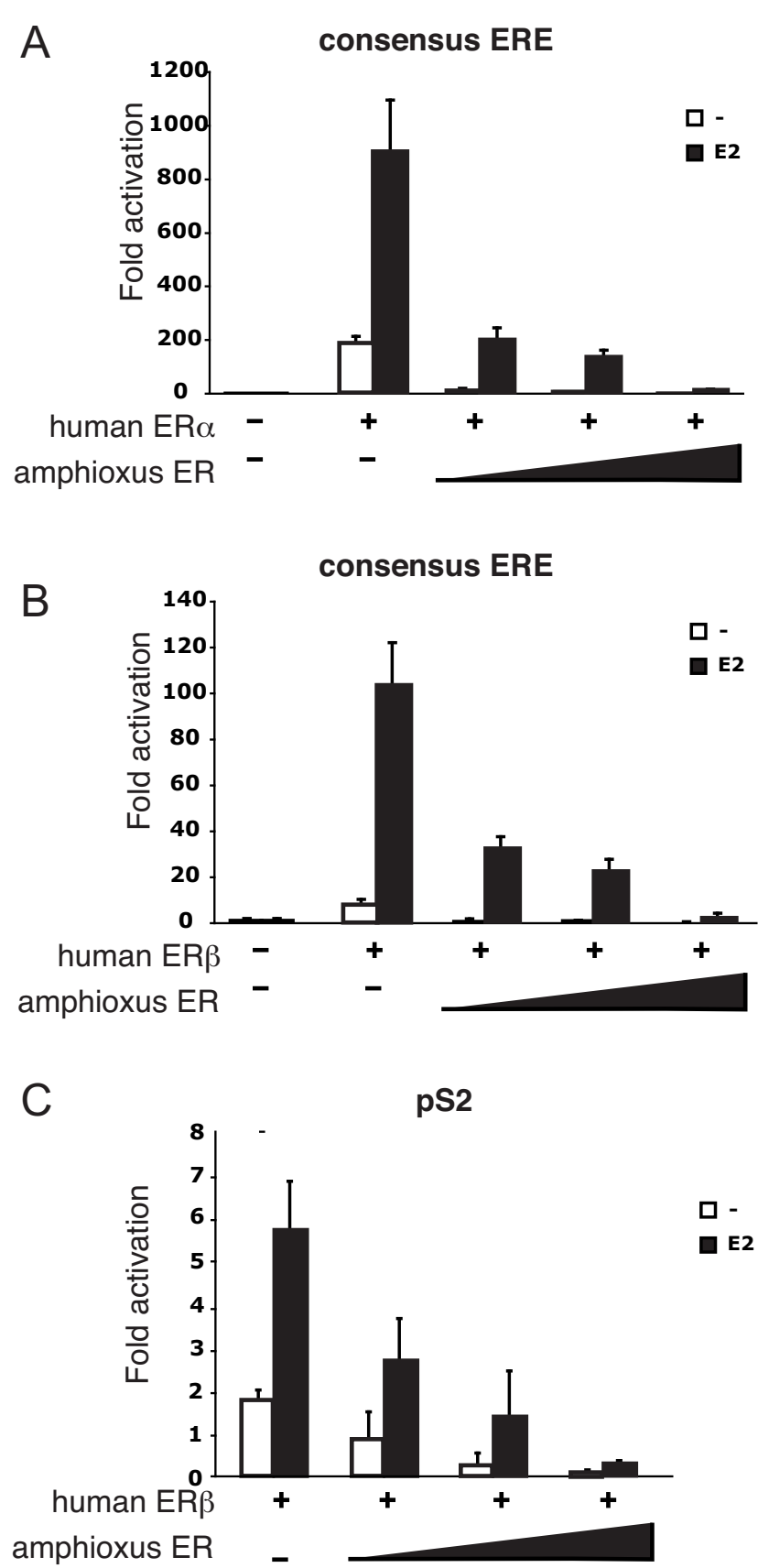

\section{Figure 5}

The amphioxus ER acts as a dominant negative estrogen receptor. $A$ PSG 5 construct containing human $E R \alpha(A)$ or human ER $\beta$ (B) was tested in transfected HeLa cells for its ability to activate the co-transfected cognate EREluc reporter plasmid after $E_{2}$ stimulation $\left(10^{-6} \mathrm{M}\right)$ in presence of increasing doses of the amphiER construct. (C) A pSG5 construct containing human ER $\beta$ was tested in transfected HeLa cells for its ability to activate the co-transfected ps 2 promoter after $E_{2}$ stimulation (I0-6M) in the presence of increasing doses of the amphiER construct. 

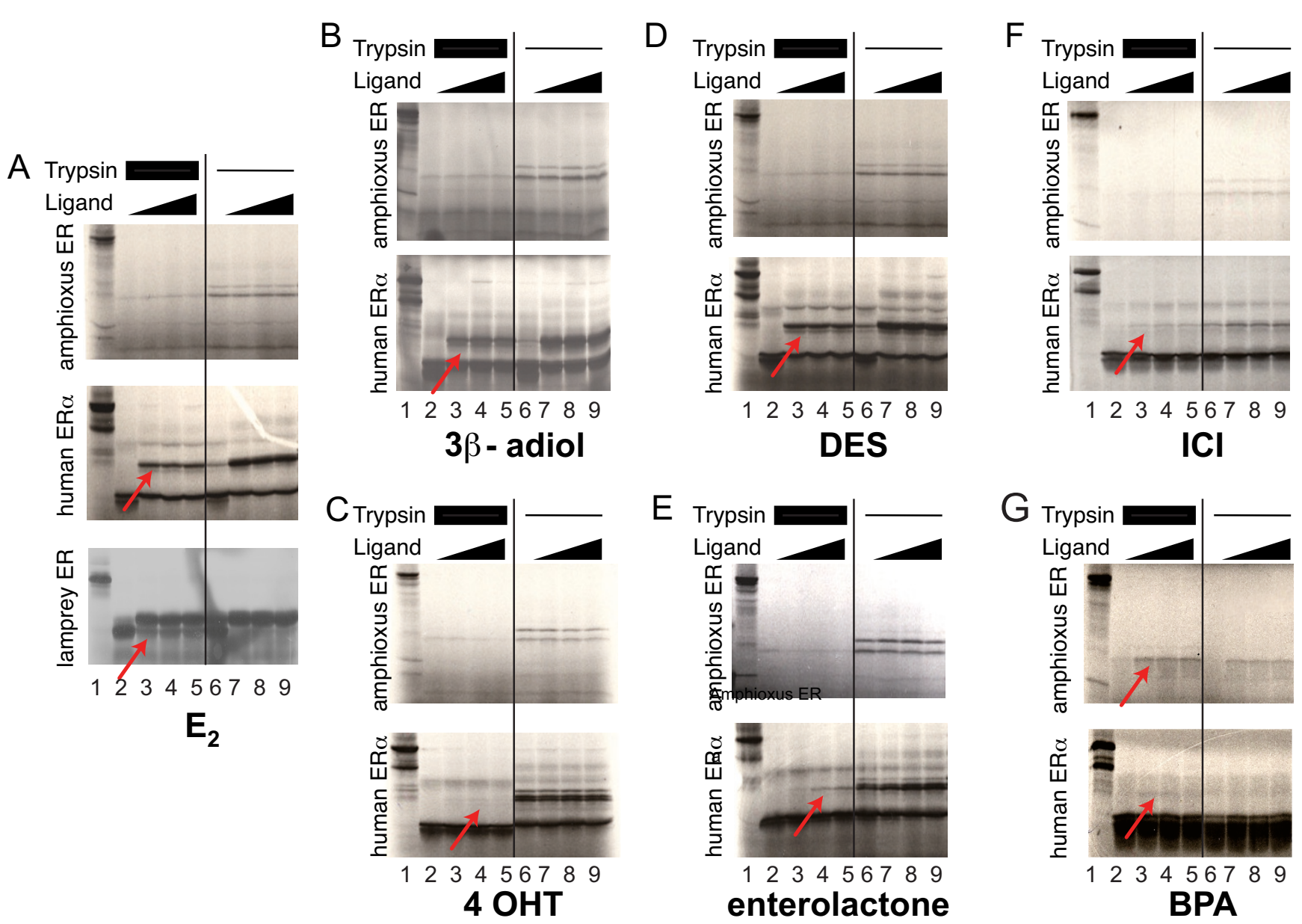

Figure 6

Limited proteolysis of lampER with $E_{\mathbf{2}}$ and of amphiER with various ER ligands. Human ER $\alpha$ was used as a positive control. lane I: undigested protein, lanes 2-5, 6-9: digested protein in the absence (lane 2 and 6) or presence (lanes 3-5 and 79) of ligand ( $10^{-3} \mathrm{M}$ to $\left.10^{-5} \mathrm{M}\right)$. 2 different trypsine doses are shown, indicated by thick or thin bars above each panel. The ligands are (A) estradiol, (B) 3ß-Androstane-diol, (C) 4-hydroxytamoxifen, (D) diethylstibestrol, (E) enterolactone, (F)ICl-I82780 and (G) bisphenol $A$.

their ability to bind and activate amphiER. None of the tested compounds, even at high doses, had any effect on amphiER transcription activity (see Additional file 5A). Accordingly, no recruitment of the coactivator SRC1 by amphiER was detected in mammalian two hybrid assays (See Additional file 5B). The most probable explanation is thus the lack of binding by those compounds to amphiER (See Additional file 6).

Taken together these results show that the ER from lamprey behaves as a "classical" ER since it binds DNA on a classical ERE and is activated by binding $\mathrm{E}_{2}$. On the other hand, though the single ER from amphioxus is able to bind the ERE, it does not bind any tested ER ligand and cholesterol derivative, except bisphenol A. However, no transcriptional activity was detected upon stimulation by any of the tested ligands. Since none of the mollusk ERs sequenced up to now binds $\mathrm{E}_{2}$ either, our data suggest that $\mathrm{E}_{2}$-binding by $\mathrm{ER}$ is restricted to vertebrates, implying that vertebrates specifically gained the ability to be regulated by $\mathrm{E}_{2}$ (see Discussion).

\section{Ancestral reconstruction of steroid receptors}

In previous analyses that discussed the evolution of ERs, it was argued that estradiol binding was an ancient function of all sex steroid receptors (SRs, comprised of ERs and NR3C members) and that the binding to other steroids was more recent, with estradiol binding ability getting restricted to ERs $[8,11]$. Those conclusions were based on the reconstruction of the ancestral SR sequence [11]. Since the finding that estradiol binding is not shared by all ERs but restricted to vertebrate ERs contradicts this hypothesis, and to get better insight into this apparent contradiction, the sequence of the ancestral steroid receptor was reesti- 
mated. When the ancestor (AncSR1) was first "resurrected", only one non-vertebrate sequence was available $[8,11]$. The impact of more non-vertebrate sequences (including amphiER) was thus tested on the reconstruction of the ancestor of steroid receptors. The sequence of the ancestral steroid receptor (AncSRa), at the node grouping ERs and NR3C, was inferred using PAML 4 [48], from the alignment described previously (the study was restricted to DBD and LBD) and the topology shown in Figure 2B. The predicted sequence resembles AncSR1 (Figure 1) with 12 out of 18 amino acids involved in ligand binding [49] being ER-like (Figure 1). However, important differences were noticed between AncSR1 and AncSRa. First one of the 3 amino acids making direct contacts with $E_{2}$ is different in AncSR1 and AncSRa: at this position, AncSR1 is vertebrate-ER like (a His residue is present at position 524 of humanER $\alpha$, located in helix H10-H11, in green in the alignment, Figure 1) whereas the amino acid is different in AncSRa and is mollusk-ER like (Tyr instead of His) and mutations at this site have been shown to impair ER $\alpha$ activity in human $[50,51]$. Second, when a phylogenetic tree is built including both ancestral sequences AncSR1 and AncSRa as well as various NR3 sequences, AncSRa branches deep in steroid receptors as expected since it was built on the same dataset (Figure 7. For a complete tree presenting all leaves, see Additional

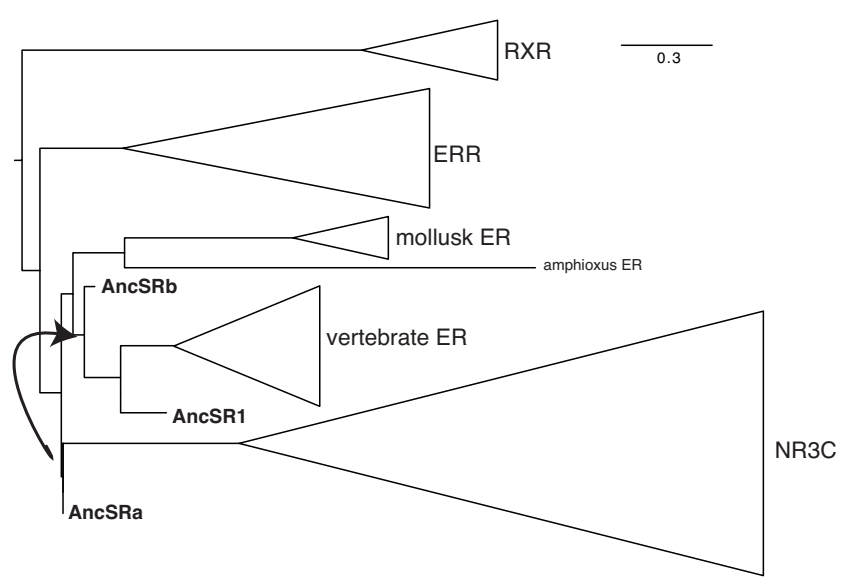

Figure 7

The reconstruction of the ancestral sequence of steroid receptors is sensitive to taxonomic sampling. The ancestral sequence of ER and NR3C was inferred using either a complete dataset (AncSRa) or a partial dataset (AncSRb) where 5 mollusk ER sequences as well as amphiER and amphiNR3C were omitted. The position of those sequences within the phylogenetic tree calculated with the complete dataset was compared. The position of a previously described ancestor (AncSRI) is indicated as well. Triangles represent the different NR clades. For the complete tree, presenting all the 80 sequences present in the tree, see Additional file 7 . file 7) but AncSR1 branches close to the vertebrate ERs, which is surprising. In order to determine whether the taxonomic sampling, and not details of the alignment, was responsible for these differences, we calculated a second SR ancestral sequence (AncSRb) using a smaller dataset: taxon sampling was reduced by removing most of the non-vertebrate steroid receptor sequences from the alignment (the amphioxus ER, the amphioxus NR3C as well as 5 out of the 6 mollusk ER sequences were removed to obtain a dataset closer to the one used in [8]). In this case, AncSRb branches next to AncSR1, closer to the ER clade than to AncSRa (Figure 7). This result clearly shows that the reconstruction of ancestral sequences is influenced by the set of sequences available and that restricted taxonomic sampling biases ancestral SR sequences towards vertebrate ER sequences. Therefore conclusions based on such an analysis (specifically that the ancestral ER was able to bind estradiol) should be considered as only tentative, since taxonomic sampling of available steroid sequences is very much vertebrate-centered. Overall, taken together, our data do no support the hypothesis that the ancestral steroid receptor was an estradiol receptor.

\section{Discussion}

\section{The amphioxus ER does not bind estradiol}

In this paper we cloned and functionally characterized the lamprey and amphioxus orthologues of the human estrogen receptors. Our results show that lampER binds estradiol whereas amphiER does not. We propose that 3 types of ERs can be distinguished, depending on their ligand binding properties: vertebrate ERs (including lamprey) are the only bona fide estradiol receptors, mollusk ERs do not bind estradiol and are constitutively active transcription factors and amphiER does not bind estradiol and is transcriptionally silent in mammalian cells. This is supported by two points: (i) the experimental approach developed here is biologically relevant since the binding of bisphenol A (BPA) to amphiER was observed using the same experimental conditions as for $\mathrm{E}_{2}$ suggesting that amphiER is correctly folded and that a ligand binding pocket is likely to be present. (ii) One of the three key amino acid positions within the LBP of amphiER (Cys 531, located between the helixes H5 and H6, in green in Figure 1) diverges from vertebrate ERs (Arg 394 in human $\mathrm{ER} \alpha$ ), whilst the two other key positions (Glu 490 and His 659 in amphiER, located in helix H3 and H10-H11 respectively, in green in Figure 1) are conserved with the vertebrate ERs (amino acids corresponding to Glu 353 and His 524 in human ER $\alpha$ ), suggesting that potential contacts between amphiER and estradiol are impaired. Accordingly, a recent in silico study of amphiER ligand binding ability confirmed an "unusual ligand recognition in amphioxus ER" [52].

It was unexpected that no effect of the synthetic ER agonist BPA was detected in the transactivation assay of the recep- 
tor in mammalian cells since BPA induces a conformational change of amphiER. This apparent absence of coactivator recruitment (see Additional file 4B) resulting in no transcriptional activity in response to BPA can be interpreted in several ways: (i) because of the different geometry of the ligand-binding pocket in amphiER, BPA behaves as an antiestrogen (partial agonist or even a partial antagonist) and blocks the transcriptional activation properties of amphiER, for instance by inducing a conformational change that does not allow coactivator recruitment (like human ER $\alpha$ and 4-raloxifen, [53]) or by excluding amphiER from nucleus (like ICI-182,780 with human ER $\alpha$, [54]). (ii) Alternatively, the coactivator interface of amphiER does not fit with mammalian coactivators, resulting in artifactual loss of activation. However, the conservation of the amino acids involved in co-activator interaction, compared to human ER $\alpha$ does not support this hypothesis (sites indicated with a star in Figure 1, as described in [55]). Among the divergent sites, at a position implicated in the charge clamp necessary for coactivator contact, amphiER contains an aspartate (D677) instead of a glutamate in humanER $\alpha$ (E542). Importantly, the divergence $(\mathrm{E}->\mathrm{D})$ is conservative and preserves the negative charge of the amino acid, which is important for interaction with the lysine from helix 3 (conserved in amphiER) to form this charge clamp [56]. In addition, a unique orthologue of the p160 family of coactivators was found in the amphioxus genome [35] and its overall conservation with its 3 human ohnologues (genes that have been duplicated during the two rounds of whole genome duplications in the chordate lineage [57]) is good. (iii) Interaction between mammalian chaperones like HSP90 and amphiER is impaired, leading to improper binding to the hormone [58]. Taking these results into account, it will be interesting to test the effect of BPA on the subcellular localization of amphiER and to study if other related compounds are able to bind and/or activate amphiER. In addition, it will be important, when cell cultures from amphioxus are available, to check the activity of amphiER in a monospecific transient transfection assay. It should be remembered that some orphan receptors such as ERRs are thought to have no natural ligands even if they are able to bind synthetic compounds [59]. More generally, the precise status of amphiER in terms of ligand binding remains an open question. It is nevertheless clear, and this is an important issue for the current evolutionary debate, that amphiER is not able to bind estradiol.

\section{Is there any receptor for estradiol in amphioxus?}

The observation that amphiER does not bind $\mathrm{E}_{2}$ is indeed a surprising observation since $\mathrm{E}_{2}$ was detected in amphioxus by RIA, the hormonal production being correlated with breeding season [15]. Several aspects of steroid metabolism were described in amphioxus [60] and the homologues of many enzymes necessary for estradiol syn- thesis in mammals were cloned from amphioxus ovaries $[15,61]$. Of particular interest is the report of an aromatase gene (CYP19) in amphioxus, which suggests that the crucial step in estradiol synthesis is indeed possible in amphioxus. These experimental data were recently confirmed by the analysis of the complete amphioxus genome sequence [35]. It may be that, in amphioxus, the active sex hormone is an $\mathrm{E}_{2}$-derivative [62] or another sex hormone, like in the case of androgens in lamprey [63], and this derivative is still to be discovered. In a similar way, we recently demonstrated that the amphioxus TR orthologue does not bind $\mathrm{T}_{3}$ or $\mathrm{T}_{4}$, the classical thyroid hormones, but deaminated derivatives TRIAC and TETRAC, which are able to induce amphioxus metamorphosis [64].

A second possibility is that $E_{2}$ itself has a central role in sex maturation in amphioxus, and that the functional estrogen receptor in amphioxus is different from amphiER. Several candidates are possible. First, there is another steroid receptor in amphioxus (amphiNR3C in Figures 1 and 2) [35] that exhibits several ER-like features. Its P- and Dboxes are closer to ERs than to vertebrate NR3C (Figure $2 \mathrm{~A})$. The sequence identity of its LBD with human ER $\alpha$ $(37 \%)$ and with NR3C members (35\%) are similar. Moreover, most of the amino acids involved in ligand binding are more ER-like than AR-, PR- or MR-like (Figure 1). However it is the only NR3C receptor (orthologous to AR, $\mathrm{PR}, \mathrm{MR}$ and GR) found in the amphioxus genome. Thus if amphiNR3C plays the role of an estradiol receptor, this suggests an absence of a "classical" steroid receptor able to bind testosterone, progesterone or corticoids. Alternatively, a non-nuclear receptor could mediate $\mathrm{E}_{2}$ action in amphioxus. Indeed, several non-genomic effects of estradiol were reported in mammals involving GPCRs (for reviews see [65-67]). For instance, very recently, a high affinity receptor for the steroid androstenedione linked to the membrane, was described in lamprey [68] and a GPCR with high affinity for progestines was isolated from sea trout [69].

\section{Implications for the evolution of ERs}

The absence of $\mathrm{E}_{2}$ binding by the amphioxus estrogen receptor has interesting consequences for the evolution of SRs and ERs. Indeed, only the well characterized gnathostome ERs and the lamprey ER (studied here) have been shown to mediate $\mathrm{E}_{2}$ action. Outside vertebrates, all the ERs studied so far (in mollusks and amphioxus) do not bind $E_{2}[11,12,24-26]$. Parsimony implies that the function of estradiol in the bilaterian ancestor was not mediated by ER and that ER had another function. Only later during evolution, in the vertebrate lineage, ER would then have gained the ability to be activated by $\mathrm{E}_{2}$ and to mediate the hormonal action of this compound (Figure 8). The alternative scenario (ancestral $\mathrm{E}_{2}$ binding and independ- 
ent loss of either ER itself or $\mathrm{E}_{2}$ binding to ER in mollusks and invertebrate deuterostomes) is more costly in terms of evolutionary events, even if the hypothesis of an NR3C orthologue binding $E_{2}$ is taken into account. Thus, taken together, our results do not support previous scenarios of steroid receptor evolution based on a reconstruction of the ancestral steroid hormone receptor AncSR1 $[8,11]$.

To describe the evolution of a protein, being able to study ancestral sequences at different nodes of a phylogeny would obviously provide historically relevant information that is not available otherwise [70]. However such sequences have disappeared long ago and can only be statistically estimated. The accuracy and bias of these estimations therefore need to be investigated. Indeed, functional studies of ancestral sequences are of any value only if the ancestral reconstruction is reliable enough. The confidence associated with the previously published ancestral steroid receptor is quite low. Indeed, the overall accuracy of the reconstruction of the LBD (AncSR1) was only 62\% [11]. This is similar for the ancestor inferred here (Anc-

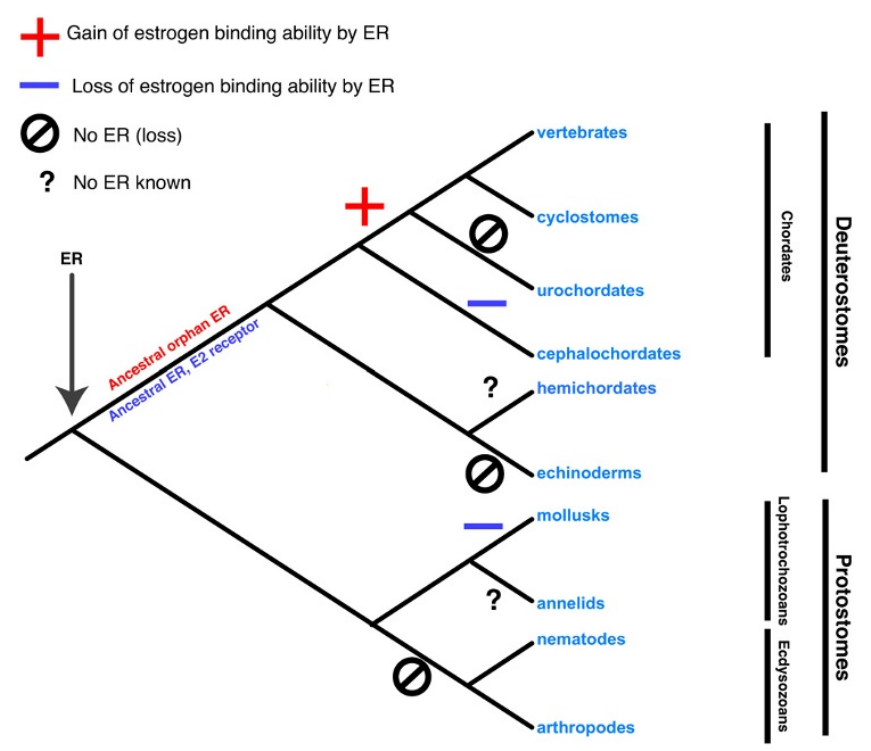

\section{Figure 8}

Model of evolution of the ligand binding ability of ERs. On a classical phylogenetic tree of bilaterians, data available on the binding ability of all known ERs have been indicated. Two hypotheses are compared in terms of parsimony, whether the ancestral ER was liganded (in blue) or not (ie an orphan receptor) (in red). This result displays different costs in terms of parsimony: one unique event of gain specifically in vertebrate for the "ancestral ER orphan" hypothesis against at least two parallel events of loss of binding for the "ancestral ER binding $E_{2}$ " hypothesis. In addition, three events of loss of the ER gene in urochordates, echinoderms and insects +nematodes are implied by the current distribution of the gene across metazoans.
SRa) on an enriched dataset, with an overall accuracy of the DBD+LBD of 70\%. Moreover, amino acid uncertainty was high at many sites of AncSRa and AncSR1: more than 60 sites have more than 1 possible amino acid with a probability superior to 0.2 . If one were to make an exhaustive study, one would need to reconstruct and test more than $10^{24}$ potential proteins (if all possible combinations of amino acids with probability $>0.2$ were tested). In fact several of the sites involved in ligand binding have low probabilities. Examples of more reliable reconstructions of nuclear receptors have been published, e.g. the ancestor of MR and GR (mineralocortoid and glucocorticoid receptors) in which the overall accuracy of the LBD was above $99 \%$, with no disrupting mutation at any site [71]. The reconstructed ancestor of RARs also showed a high average confidence (99\% [13]). This discrepancy between results obtained on the ancestor of all steroid receptors or merely of MR and GR for instance, can be explained by the higher sequence divergence observed among all SRs than simply among subfamilies MR and GR (see branch length in Figure 2B). Consequently, the uncertainty associated to the sequence of the ancestral steroid receptor as estimated with nowadays methods is probably too high to provide a firm basis for evolutionary conclusions. Moreover, the phylogenetic reconstruction of ancestral sequences has been shown to be biased towards the most frequent (and more stable) amino acids, resulting in an under-estimation of the less frequent amino acids (the stability of the ancestral protein is then over-estimated [72]). In reconstructions of ancient proteins, where the evolutionary signal has been lost due to a high number of substitutions, such biases might be problematic. Thus, current reconstruction methods do not seem powerful enough to infer a biologically meaningful ancestral steroid receptor given the amount of divergence between sequences.

Nonetheless, all these reservations put aside, it is surprising that the previously reconstructed ancestral SR, is vertebrate ER-like. As almost all the extant sequences used as matrix for the reconstruction came from vertebrates and led to the estimation of a "vertebrate-like" ancestral sequence, the same ancestral steroid receptor as previously published [11] was estimated, but adding more sequences from various taxa. This reconstruction was done using a phylogeny equivalent to the one previously published [11]. Using this approach, the new AncSRa is more divergent from vertebrate ERs than AncSR1. Interestingly AncSR1 was shown to bind $\mathrm{E}_{2}$ with a very low affinity (250 times lower affinity than human ER $\alpha$ [11]), suggesting that AncSRa may be an even worse estradiol receptor.

The bias of AncSR1 towards vertebrate ERs is explained by a lack of non-vertebrate sequences used for the reconstruction. Indeed, removing some non-vertebrate sequences 
from our dataset leads to an estimation of an ancestral steroid receptor that is more "vertebrate ER"-like (AncSRb in Figure 7). The clustering of AncSRb with the ER clade and the exclusion of AncSRa from the ER clade were supported with good statistical values (minimum of Chi2based and SH-like supports of 0.83 and 0.89 , respectively). Those data show that AncSR1 reconstruction was probably sensitive to the vertebrate bias in the data set (Figure 7). Overall, we suggest that analysis based on ancestral reconstructions should be taken as tentative, especially in case of low statistical confidence and limited taxonomic sampling. In case of the ancestral steroid receptor, even if exhaustive taxonomic sampling is necessary, phylogenetic signal is weak and the resulting confidence is quite low. Thus we think that even if the ancestral sequence built here is biologically more relevant than previously calculated ones (because of better taxonomic sampling), it remains quite uncertain. Consequently conclusions regarding the ancestral steroid receptor should be based mostly on comparative characterization of extant receptors. In that case, all the data based on invertebrate ER receptors (from mollusks and amphioxus) support an ancestor of steroid receptors that was not able to bind estradiol. This conclusion will obviously require the functional characterization of ERs from other protostome phyla in order to carefully check if this observation is general. Thus, available data converge towards a re-evaluation of the ancestral status of estrogen receptors.

\section{Sequence conservation reflects functional constraints: ligand binding ability is more recent than DNA-binding ability}

From our and previous studies, only vertebrate ERs are able to bind and activate transcription under estradiol stimulation $[11,12,24-26]$. The LBD of amphiER is more divergent from its vertebrate counterparts (ca. 34\% amino acid identities) than the LBD of other liganded amphioxus nuclear receptors such as amphiRAR (ca. 58\%), which has been shown to bind the same ligand as its vertebrate homologue $[7,13]$. This suggests that a conserved functional feature (e.g. binding to the same ligand) is reflected in the sequence conservation of the LBD.

The same observation can be done concerning the DBD since all ERs, including amphiER, have a highly conserved DBD and are able to bind EREs. Thus, for this domain also, a conservation of the function is reflected in sequence conservation.

Accordingly with this notion, the LBD of invertebrate ERs is highly divergent but their DNA binding domain, as well as other functionally important domains not directly linked to ligand binding such as the dimerization interface, or the amino acids responsible for interaction with the co-activators [55] are well conserved. This is true for amphiER as well as mollusk ERs. This strongly suggests that amphiER is a bona fide NR regulating ERE-containing genes in an $\mathrm{E}_{2}$-independent manner. Post-translational modifications such as phosphorylation or the presence/ absence of other receptor-interacting proteins such as transcriptional coactivators have been shown to regulate unliganded nuclear receptors [73]. Whether one of these mechanisms acts to regulate the activity of invertebrate ERs or if those receptors have unknown ligands still to be identified remains to be explored. Anyway our observations strongly suggest that for ERs, the DNA binding function of the receptor as well as its interaction with coregulators have been conserved due to selective pressure. Interestingly, when studying the AncSRa, the P- and Dboxes in the DBD are ER/ERR-like (Figure 1), suggesting that ER/ERR DNA binding ability is ancestral, in accordance with the fact that these are the only receptors of the NR3 family found in invertebrates. This difference in the selection pressure between DBD and LBD has been proposed to be a general evolutionary pattern for the whole NR family [7]. The plasticity of the ligand binding ability of NRs was recently illustrated in the case of RXR-USP where the ability of the receptor to be regulated by a ligand was suggested to have been subject to several successive episodes of gain and loss during evolution [74].

\section{Evolution of endocrine systems: refinement of the ligand exploitation model}

The ligand exploitation model hypothesizes how new hormones and new receptors appear during evolution. It suggests that the ancestral ligand is the last metabolite of a synthesis pathway [8]. According to this model, the ancestral steroid ligand was estradiol (and the ancestral SR bound estradiol). During evolution, other steroid receptors appeared by duplication of the ancestral ER and gained the ability to bind other steroids, intermediate in the synthesis pathway (like testosterone or progesterone).

Our findings on the evolution of ERs do not support the ligand exploitation model, since our data strongly suggest that the ancestral ER did not bind estradiol. However, as estradiol has been detected in deuterostomes as well as protostomes (for instance in vertebrates, amphioxus, echinoderms, mollusks, for review, see [75]), steroid signaling may have been already present in bilaterian ancestor. However, up to now, the ancestral steroid molecule remains to be determined. If estradiol is an ancient hormone, it then probably bound another receptor and later on ER gained the ability to recognize it, as did other steroid receptors for their extant ligand. Thus the evolution of steroid system intermingles two distinct processes, the evolution of the receptor on one hand, and the evolution of the ligand on the other.

The receptor can evolve by point mutations and change its affinity for a ligand towards another. This idea was convincingly exemplified in the case of corticoid receptors 
(the ancestor of MR and GR) for which it was recently demonstrated that ability of the ancestral vertebrate corticoid receptor to bind gnathostome-specific hormone aldosterone (a MR ligand) was a by-product of its ability to bind the ancestral ligand 11-deoxycorticosterone (DOC) [71]. GR gained the ability to bind cortisol only in the gnathostome lineage, in parallel to endogenous synthesis of the hormone [16,71]. This detailed study shows that a receptor binding a given ligand can acquire affinity for compounds present in the cell that are structurally close to its natural ligand: this refines the ligand exploitation model, since new ligands are not necessarily precursors of ancient ligands, simply compounds present in the cell and structurally close to the ancestral ligand. Similar conclusions were drawn previously in the case of RAR evolution [13]. It has to be emphasized that the pool of available compounds is also subject to evolutionary changes in parallel. For instance, the spatiotemporal production of estradiol is variable in the different vertebrate groups (reviewed in [76]). Glucocorticoids differ in mouse (cortisol) and in human (corticosterone), with both hormones being GR ligands [77]. There are several androgens in teleost fishes, with 11-ketotestosterone being teleost-specific [78]. As there are 2 androgen receptors (ARs) in teleost fishes, from a whole genome duplication [79], the study of the ligand-binding ability of those ARs is a potentially interesting case for the evolution of endocrine systems. As highlighted by Bridgham et al. (2006), lamprey does not produce cortisol [71]. In accordance, their genomes do not contain the sequence corresponding to the enzyme responsible for cortisol synthesis (11b-hydroxylase) and in general classical steroids except estradiol are rarely found in lamprey. This suggests that the steroids actually found in lamprey are different from the ones found in mammals (reviewed in [80]). Those cases exemplify the largely underestimated diversity of endocrine systems: except for lamprey and some teleost fishes, the hormonal pool of animals remains largely unknown. As proposed for the study of steroid receptors, a comparative approach should be applied to determine the metabolism of steroids in poorly studied animals. Indeed, the hormonal pool of such animals is usually evaluated from the presence/absence of putative orthologues of mammalian enzymes. As the enzymatic machinery involved in hormonal metabolism has a very labile activity (reviewed in $[81,82])$, equating orthology with functional identity might be unreliable.

The evolution of steroid receptors can be replaced in the more general context of ligand-nuclear receptor co-evolution. The evolution of the NR1H subfamily, that includes receptors for other steroidal compounds, like the major transcriptional regulator of bile salt synthesis farnesoid $x$ receptor (FXR), the pregnane $\times$ receptor (PXR), the vita- min D receptor (VDR) or liver $\times$ receptor (LXR)/ecdysone receptor (Ecr), has been extensively studied and is not in line with the ligand exploitation model [83-85]. For instance, comparative functional studies of FXRs from various chordate species showed that the vertebrate FXRs bind "late" cholesterol derivatives (from a complex synthesis pathway) but are thought to have evolved from an ancestral FXR that bound early cholesterol derivatives (from a simpler synthesis pathway) [83].

In other cases, the evolution of ligand binding is more "chaotic" with close orthologs having a selective ligand binding ability that varies extensively (vertebrate VDRs are very well conserved when PXRs have the widest ligand repertoire of all NRs) [83].

These complex histories are probably linked to specific function of some of those NRs, considered as xenotoxic compounds "sensors". This tight relationship with the unstable environment probably makes receptors like FXR and especially PXR more prone to fast evolution [86]. Yet they illustrate the impressive variety of scenarios of NR evolution.

\section{Conclusion}

In this article, we demonstrated that vertebrate ERs (including lamprey ER) are estradiol receptors whilst nonvertebrate ER (including amphioxus ER) are not. The most parsimonous scenario proposes that the ancestral ER was not able to bind estradiol and that it had another function. It later gained the ability to be regulated by estradiol, specifically in the vertebrate lineage. However, additional critical data remains to be discovered in poorly studied taxa [62]. To fully understand the evolution of steroid signaling pathway, a larger number of taxa need to be targeted for detailed comparative studies. More precisely, ERs and other steroid receptors should be cloned from widely distributed taxa, especially in protostomes. Enzymes involved in steroidogenesis should also be cloned and characterized, to understand the evolution of steroid availability. In order to avoid the blinders of a "vertebrate-centered" view, it is of particular importance to establish the steroid hormone repertoire of an enlarged animal panel, including more protostomes. The description of various endocrine systems will certainly be relevant to the early evolution of hormone signaling.

\section{Methods}

\section{Cloning of amphiER}

An initial piece of amphiER was obtained by degenerate PCR on different RT reactions from total RNA extracted either from developing $B$. floridae embryos and larvae (at $13 \mathrm{~h}-15 \mathrm{~h}, 28 \mathrm{~h}, 36 \mathrm{~h}, 48 \mathrm{~h}$ or $3 \mathrm{~d}-4 \mathrm{~d}$ of development) or from B. floridae adults. The oligonucleotides used were 
as follows: forward primer 5'-TGYGARGGITGYAARGCITTYTT-3' and reverse primer 5'-GTRCAYTSRTTIGTIGCIGGRCA-3'.

The touchdown PCR program used was as follows:

5' 94 degrees

$5 \times$ (30" 94 degrees, 1' 55 degrees, 1' 72 degrees)

$5 \times$ the same cycle, but at 50 degrees annealing temperature

$5 \times$ the same cycle, but at 45 degrees annealing temperature

$5 \times$ the same cycle, but at 40 degrees annealing temperature

$25 \times$ the same cycle, but at 37 degrees annealing temperature

$7^{\prime} 72$ degrees

All degenerate PCRs irrespective of the RT reaction template used yielded a $83 \mathrm{bp}$ fragment of amphiER. The fragment was sequenced on both strands and used for the design of oligonucleotides for 5' and 3' RACE experiments with the Invitrogen GeneRacer Kit. The template for the RACE experiments was pooled total RNA from $13 \mathrm{~h}-15 \mathrm{~h}$ B. floridae embryos and from B. floridae adults. In addition to the oligonucleotides provided by the kit, for the 3' RACE, the following primers were used:

\section{3' RACE, 1st PCR: 5'-AACGGAGCATTCAGCAAGGTC-3' \\ 3' RACE, 2nd PCR: 5'-GCATTCAGCAAGGTCAGACAG-3' \\ 5' RACE, 1st strand cDNA synthesis: 5'-ATGTAATCT- GTCTGACCTTGC-3'}

\section{5' RACE, 1st PCR: 5'-CTGTCTGACCTTGCTGAATGC-3' \\ 5' RACE, 2nd PCR: 5'-TCTGACCTTGCTGAATGCTCC-3'}

The protocols for the 1 st and 2 nd round of PCR experiments are given in the Invitrogen GeneRacer Kit. The 3' and 5' RACE products were subsequently sequenced on both strands and used for the design of oligonucleotides for the full-length cloning of amphiER: forward primer 5 'CGGCGAAGCGAAGAAGATCGAG-3' and reverse primer 5'-CTTAACCGATACTAACGGAACAG-3'. The full-length amphiER was obtained by PCR on pooled RT reactions from total RNA extracted from B. floridae $13 \mathrm{~h}-15 \mathrm{~h}$ embryos, 3 d-4 d larvae and B. floridae adults. The PCR protocol used was as follows:

10' 94 degrees

$5 \times$ (30" 94 degrees, 30" 55 degrees, 2' 72 degrees)

$35 \times$ the same cycle, but at 50 degrees annealing temperature

10' 72 degrees

The full-length amphiER clone resulting from this PCR is 2279 bp long, was cloned into the pCR2.1 vector (Invitrogen) and subsequently sequenced on both strands.

\section{Plasmid constructs and reagents}

Full length amphiER were amplified by polymerase chain reaction (PCR) and the obtained fragments were inserted into a PSG5 vector between EcoR1 sites. Lamprey ER was a generous gift from JW Thornton. Human pSG5-ER $\alpha$ and pSG5-ER $\beta$ and the 3xERE-Luc luciferase reporter construct have been described previously [87]. The pS2-Luc reporter construct encompasses an 1100 bp estrogen-responsive region of the human pS2 promoter inserted into the pGL3 basic vector (Promega). Chimeras comprising the GAL4 DNA-binding domain fused with the LBD of the human ER $\alpha$ (residues 251 to 595), the LBD of amphiER (residues 364 to 705 ), the LBD of lampER (residues 234 to 554) have been cloned in the pG4MpolyII vector. $17 \beta$-estradiol, genistein, 3 $\beta$-androstenediol, resveratrol, cholesterol, cholic acid, chenodeoxycholic acid, $22^{\circledR}-$ hydroxycholesterol, 20-Hydroxyecdysone, pregnenolone, trans-Dehydroandrosterone (DHEA), corticosterone, progesterone, 4-androstene-3,17-dione, estrone, testosterone, $5 \alpha$-androstan-17 $\beta$-ol-3-one and 1a,25Dihydroxyvitamin D3 (calcitriol) were purchased from Sigma. Enterolactone was a generous gift from Dr Sari Mäkelä [88].

\section{Phylogenetic analysis of NR3}

Protein sequences of NR3 family members were obtained from GenBank by BLAST search using Homo sapiens ER $\alpha$ as a query. Eight additional sequences from the closely related RXR group were also obtained to serve as outgroup sequences. For accession numbers of the sequences used, see Additional file 8.

The retrieved sequences were aligned using the muscle 3.6 program [89] and the resulting alignment was manually corrected with SEAVIEW [90]. Phylogenetic tree was calculated by maximum likelihood as implemented in PhyML version 2.4.3 under a JTT substitution matrix plus a eightcategory gamma rate correction ( $\alpha$ estimated) and with the proportion of invariant sites estimated. Both the DBD 
and the LBD were used. Robustness was assessed by bootstrap analysis (1,000 repetitions) [91].

The Bayesian inference was done using the program MrBayes 3.1.2 [92]. Two simultaneous independent runs were performed. For each run, one chain was sampled every 100 generations for 1,000,000 generations after the burn-in cycles, until the average SD of split frequencies was $<0.01$; additionally, the potential scale reduction factors of the parameters were close to or equal to 1 , which indicates that the runs had most probably converged. The neighbour-joining (Poisson correction) and maximum parsimony trees were done with Phylo_win [90].

\section{Likelihood-based tests of alternative topologies placing amphiER at all possible positions in the tree}

The 149 trees were built by reconnecting amphiER from the maximum likelihood tree, into the 149 possible positions. The branch length and the different parameters of the obtained trees were re-estimated using PhyML. Likelihood-based tests of the 149 alternative topologies were calculated using CONSEL: site-wise log-likelihood values, available as output of PhyML, were used to calculate the P-values of the different positions according to the AU test with the software $\mathrm{R}$.

\section{Ancestral sequence reconstruction}

The aminoacid sequence of the ancestral AncSRa and Anc$\mathrm{SRb}$ was inferred only for the most conserved part of the alignment, i.e. the DBD and LBD (defined as in Figure 1). The ancestral sequences were reconstructed by maximum likelihood as implemented in PAML [48], under the JTT substitution model and a gamma distribution with 8 categories of rates across sites, using the tree described in Additional file 1A for AncSRa and a the same topology truncated of the mollusk ER sequences and the amphioxus NR3 sequences, after reestimation of the branch lengths using phyml $(J T T+\gamma)$ for AncSRb.

\section{Electrophoretic Mobility Shift Assay (EMSA)}

EMSAs were performed as previously described [93]. Where indicated, a 10- and 100-fold molar excess of 30bp unlabeled oligonucleotides (a consensus ERE and a non-related probe) were added as competitors. The sequence of the probe containing the consensus ERE is 5'CGGGCCGAGGTCACAGTGACCTCGGCCCGT-3' and the sequence of the non-related probe is 5'-CTAGTCCTAGGTCTAGAGAATTCA-3'.

\section{Cell culture and transfections}

Human embryonic kidney 293 cell culture and transfections using Lipofectamine Plus reagent (Invitrogen) were done according to the manufacturer's recommendations and as previously described [94]. Briefly, $200 \mathrm{ng}$ of the chimeras comprising the GAL4 DNA-binding domain fused with the LBD of either human ER $\alpha$, lampER or AmphiER (or LBD for the control) were co-transfected together with $100 \mathrm{ng}$ of reporter plasmid and $10 \mathrm{ng}$ of a $\beta$ galactosidase expression vector, included as a control for transfection efficiency. For the mammalian double hybrid assays, the GAL4-amphiER-LBD chimera was transfected with $200 \mathrm{ng}$ of the coactivator SRC1 fused to the strong activation domain VP16. Three to five hours post-transfection, serum and hormones (as indicated in the figures) were added to the cells which were incubated for an additional 48 hours before harvest and luciferase and $\beta$-galactosidase activities were determined. Results show the mean \pm s.e.m. $(n=3)$ of representative experiments. Human HeLa cervical cancer cells and CV-1 green monkey kidney cells were routinely maintained in Dulbecco's modified eagle's medium (Invitrogen), supplemented with $10 \%$ fetal bovine seum, $1 \% \mathrm{v} / \mathrm{v}$ L-glutamine and $1 \%$ $\mathrm{v} / \mathrm{v}$ penicillin/streptomycin. Cells were seeded in 12 or 24 well plates one day prior to transfection. Transient transfections were carried out using the Lipofectamine Plus reagent according to instructions of the manufacturer (Invitrogen) in culture media devoid of serum, phenolred and antibiotics. Briefly, 1 ng of ER $\alpha, E R \beta$ or AmphiER expression vectors were co-transfected together with 100 ng 3xERE-Luc (or 200 ng pS2-Luc where indicated) and 20 ng of a $\beta$-galactosidase expression vector, included as a control for transfection efficiency. In the co-expression experiments, AmphiER was co-transfected together with $\mathrm{ER} \alpha$ or ER $\beta$ in ratios of $0.5: 1,1: 1$ and $1: 5$, respectively. Three hours post-transfection, serum and hormones (as indicated in the figures) were added to the cells which were thereafter incubated for an additional 48 hours before harvest and luciferase and $\beta$-galactosidase activities were determined. Figures represent results from at least three independent experiments performed in duplicates. Data is presented as mean +/- SD of fold induction of relative luciferase values corrected against $\beta$-galactosidase activity, where activity obtained from transfected reporter plasmid alone and treated with vehicle, was arbitrarily set to 1 .

\section{Limited proteolytic digestion}

These assays were done as previously described [13].

\section{Authors' contributions}

$\mathrm{MP}, \mathrm{HE}, \mathrm{MS}, \mathrm{SB}$ and VL contributed to the conception and design of the study. MS cloned amphiER. MP performed the EMSA, limited proteolysis experiments, part of the transactivaton assays and the bioinformatics study. KP and IP performed the rest of the transactivation assays. MP and VL wrote the manuscript. 


\section{Additional material}

\section{Additional file 1}

Phylogenetic analysis of NR3 sequences using several methods. Phylogenetical trees of an alignment comprising 69 NR3 sequences as well as RXR sequences were inferred using the maximum likelihood method $(M L)(A)$, Bayesian analysis (B), neighbour-joining method (C) and maximum parsimony method (MP) (D) based on an elision alignment of the DBD and LBD of 77 NR3 and RXRs (accession numbers are given in Additional file 8). Labels above each branch show percentages of bootstrap values after 1000 replicates (A), posterior probabilities (B), percentages of bootstrap values after 500 replicates (C) or 100 replicates (D). The fastest evolving sites (with an evolutionary rape above 2, as indicated in the Figure 3A) were removed from the alignment before computing phylogeny by maximum parsimony, to preserve the branching of mollusk ERs within the ER clade. In (A) nodes with bootstrap values below $50 \%$ are presented as polytomies, as in the Figure $2 B$.

Click here for file

[http://www.biomedcentral.com/content/supplementary/14712148-8-219-S1.pdf]

\section{Additional file 2}

DNA binding characterization of chordate ERs. Various chordate members of the NR3 family, namely human ER $\alpha$, human ER $\beta$, mouse ERR $\alpha$, amphiER and lamprey $E R$, were synthesized in vitro and allowed to bind to a ${ }^{32}$ P-labeled consensus ERE probe in an EMSA. Lane 1, empty vector (pSG5) reticulocytes lysates. Lanes 2-5, human ER $\alpha$. Lanes 6-9, human ER $\beta$. Lanes 10-13, mouse ERR $\alpha$. Lanes 14-17, amphiER. Lanes 18-21, lamprey ER. Lanes 3-5, 7-9, 11-13, 15-17, 19-21, unlabeled non-specific oligonucleotide (NS) or ERE were added at indicated molar excess as competitors to test the specificity of the binding. The arrows indicated the gel shift induced by amphiER binding the ERE probe. The asterisk indicates free ERE probe.

Click here for file

[http://www.biomedcentral.com/content/supplementary/14712148-8-219-S2.pdf]

\section{Additional file 3}

The amphioxus ER acts as a dominant negative estrogen receptor in CV1 cells. A pSG5 construct containing human ER $\alpha$ (A) or human ER $\beta$ (B) was tested in transfected CV1 cells for its ability to activate the cotransfected cognate ERE-luc reporter plasmid after $E_{2}$, genistein or $\beta$ Androstane-diol stimulation $\left(10^{-6} \mathrm{M}\right)$ in presence of increasing doses of the amphiER construct.

Click here for file

[http://www.biomedcentral.com/content/supplementary/1471-

2148-8-219-S3.pdf]

\section{Additional file 4}

The amphioxus ER is not activated by BPA. (A) GAL4-LBD constructs from several chordate ERs were tested in transfected 293 cells for their ability to activate a $(17 \mathrm{~m}) 5 x$-G-luc reporter plasmid in the presence of increasing doses of BPA $\left(10^{-9} \mathrm{M}\right.$ to $\left.10^{-6} \mathrm{M}\right)$. (B) Representation of the mammalian two-hybrid SRC1 recruitment assay. The GAL4-amphiER$L B D$ chimera was used with the coactivator SRC1 fused to the strong activation domain VP16 to transfect 293 cells in the presence of increasing doses of $B P A\left(10^{-9} \mathrm{M}\right.$ to $\left.10^{-6} \mathrm{M}\right)$.

Click here for file

[http://www.biomedcentral.com/content/supplementary/14712148-8-219-S4.pdf]

\section{Additional file 5}

amphiER is not activated by cholesterol derivatives. (A) The GAL4amphiER-LBD chimera was tested in transfected 293 cells for its ability to activate a (17 m)5x-G-luc reporter plasmid in the presence of various cholesterol derivatives at a high concentration $(1 \mu \mathrm{M})$ (black). The empty vector (white) was used as a negative control and the GAL4-humanER $\alpha$ $L B D$ in the presence of $E_{2}$ was used as a positive control (B) Representation of the mammalian two-hybrid SRC1 recruitment assay. The GAL4amphiER-LBD chimera was used with the coactivator SRC1 fused to the strong activation domain VP16 to transfect 293 cells in the presence of various cholesterol derivatives at $1 \mu \mathrm{M}$. The empty vector (white) was used as a negative control.

Click here for file

[http://www.biomedcentral.com/content/supplementary/14712148-8-219-S5.pdf]

\section{Additional file 6}

Limited proteolysis of amphiER with various cholesterol derivatives. lane 1: undigested protein, lanes 2-4, 5-7: digested protein in the absence (lane 2 and 5) or presence (lanes 3-4 and 6-7) of ligand $\left(10^{-3} \mathrm{M}\right.$ and $\left.10^{-4} \mathrm{M}\right) .2$ different trypsine doses are shown, indicated by thick or thin bars above each panel. The ligands are cholic acid (A), Chenodeoxycholic acid (B), 22R-OH-cholesterol (C), cholesterol (D), 4-androstene-3,17dione $(E)$, DHEA $(F)$, corticosterone $(G)$, progesterone $(H)$, pregnenolone $(I)$, estrone $(J)$, testosterone $(K), 5 \alpha$-androstane-dione $(L), 20$ hydroxyecdysone $(\mathrm{M})$ and calcitriol $(\mathrm{N})$.

Click here for file

[http://www.biomedcentral.com/content/supplementary/14712148-8-219-S6.pdf]

\section{Additional file 7}

Phylogenetic tree of NR3 sequences as well as ancestral sequences. Complete tree corresponding to the simplified one presented in the figure 7. The ancestral sequence of ER and NR3C was inferred using either a complete dataset (AncSRa) or a partial dataset (AncSRb) where 5 mollusk ER sequences as well as amphiER and amphiNR3C were omitted. The position of those sequences within the phylogenetic tree calculated with the complete dataset was compared. The position of a previously described ancestor (AncSR1) is indicated as well. Minimum of Chi2based and SH-like supports are shown for each branch.

Click here for file

[http://www.biomedcentral.com/content/supplementary/14712148-8-219-S7.pdf]

\section{Additional file 8}

Accession number of sequences used for phylogenetic analyses. AR: androgen receptor; ER: estrogen receptor; ERR: estrogen related receptor; GR: glucocorticoid receptor; MR: mineralocorticoid receptor; PR: progesterone receptor; $R X R$ : retinoid $\times$ receptor.

Click here for file

[http://www.biomedcentral.com/content/supplementary/14712148-8-219-S8.pdf]

\section{Acknowledgements}

We thank Bastien Boussau for help with phylogenetic analysis and for comments on the manuscript. We are grateful to Joseph Thornton for the gift of the lamprey ER clone, Gerard Benoit and Gabriel Markov for critical reading of the manuscript. This work was supported by the EU funded CASCADE network of excellence, CNRS, UCB Lyon I, ENS de Lyon and MENRT. 


\section{References}

I. Gronemeyer H, Gustafsson JA, Laudet V: Principles for modulation of the nuclear receptor superfamily. Nat Rev Drug Discov 2004, 3:950-964.

2. Laudet V, Gronemeyer H: The Nuclear Receptor FacsBook. London: Academic Press; 2005

3. Germain P, Staels B, Dacquet C, Spedding M, Laudet V: Overview of nomenclature of nuclear receptors. Pharmacological reviews 2006, 58:685-704.

4. Benoit G, Cooney A, Giguere V, Ingraham H, Lazar M, Muscat G, PerImann T, Renaud JP, Schwabe J, Sladek F, Tsai MJ, Laudet V: International Union of Pharmacology. LXVI. Orphan nuclear receptors. Pharmacological reviews 2006, 58:798-836.

5. Dhe-Paganon S, Duda K, Iwamoto M, Chi YI, Shoelson SE: Crysta structure of the HNF4 alpha ligand binding domain in complex with endogenous fatty acid ligand. The Journal of biological chemistry 2002, 277:37973-37976.

6. Wisely GB, Miller AB, Davis RG, Thornquest AD Jr, Johnson R, Spitzer T, Sefler A, Shearer B, Moore JT, Miller AB, Willson TM, Williams SP: Hepatocyte nuclear factor 4 is a transcription factor that constitutively binds fatty acids. Structure 2002 10:1225-1234

7. Escriva $H$, Delaunay $F$, Laudet $V$ : Ligand binding and nuclear receptor evolution. Bioessays 2000, 22:717-727.

8. Thornton JW: Evolution of vertebrate steroid receptors from an ancestral estrogen receptor by ligand exploitation and serial genome expansions. Proceedings of the National Academy of Sciences of the United States of America 200I, 98:567I-5676.

9. Escriva $H$, Bertrand $S$, Laudet $V$ : The evolution of the nuclear receptor superfamily. Essays in biochemistry 2004, 40: I I-26.

10. Krylova IN, Sablin EP, Moore J, Xu RX, Waitt GM, MacKay JA, Juzumiene D, Bynum JM, Madauss K, Montana V, Lebedeva L, Suzawa M, Williams JD, Williams SP, Guy RK, Thornton JW, Fletterick RJ, Willson TM, Ingraham HA: Structural analyses reveal phosphatidyl inositols as ligands for the NR5 orphan receptors SF-I and LRH-I. Cell 2005, I 20:343-355

II. Thornton JW, Need E, Crews D: Resurrecting the ancestral steroid receptor: ancient origin of estrogen signaling. Science 2003, 30 I(5640): I7| 4- I7I7.

12. Keay J, Bridgham JT, Thornton JW: The Octopus vulgaris estrogen receptor is a constitutive transcriptional activator: evolutionary and functional implications. Endocrinology 2006, 1 47:386I-3869.

13. Escriva H, Bertrand S, Germain P, Robinson-Rechavi M, Umbhauer $M$, Cartry J, Duffraisse M, Holland L, Gronemeyer H, Laudet V: Neofunctionalization in vertebrates: the example of retinoic acid receptors. PLoS genetics 2006, 2:e 102

14. Baker ME: Evolution of adrenal and sex steroid action in vertebrates: a ligand-based mechanism for complexity. Bioessays 2003, 25:396-400.

15. Mizuta T, Kubokawa K: Presence of sex steroids and cytochrome P450 (CYP) genes in amphioxus. Endocrinology 2007.

16. Ortlund EA, Bridgham JT, Redinbo MR, Thornton JW: Crystal structure of an ancient protein: evolution by conformational epistasis. Science 2007, 3 I 7(5844): I544-I548.

17. Fox JE, Bridgham JT, Bovee TF, Thornton JW: An evolvable oestrogen receptor activity sensor: development of a modular system for integrating multiple genes into the yeast genome. Yeast (Chichester, England) 2007, 24:379-390.

18. Escriva H, Safi R, Hanni C, Langlois MC, Saumitou-Laprade P, Stehelin $D$, Capron A, Pierce R, Laudet V: Ligand binding was acquired during evolution of nuclear receptors. Proceedings of the National Academy of Sciences of the United States of America 1997. 94:6803-6808

19. Laudet V: Evolution of the nuclear receptor superfamily: early diversification from an ancestral orphan receptor. Journal of molecular endocrinology 1997, 19:207-226.

20. Baker ME, Chandsawangbhuwana C: Analysis of 3D models of octopus estrogen receptor with estradiol: evidence for steric clashes that prevent estrogen binding. Biochem Biophys Res Commun 2007, 36 1:782-788.

21. Baker ME: Amphioxus, a primitive chordate, is on steroids: evidence for sex steroids and steroidogenic enzymes. Endocrinology 2007, | 48:355|-3553.
22. Baker ME: Recent insights into the origins of adrenal and sex steroid receptors. Journal of molecular endocrinology 2002 , 28: $149-152$.

23. committee NRN: A unified nomenclature system for the nuclear receptor superfamily. Cell 1999, 97:I6I-I63.

24. Kajiwara M, Kuraku S, Kurokawa T, Kato K, Toda S, Hirose H, Takahashi S, Shibata Y, Iguchi T, Matsumoto T, Miyata T, Miura T, Takahashi $Y$ : Tissue preferential expression of estrogen receptor gene in the marine snail, Thais clavigera. Gen Comp Endocrino 2006, 148:315-326.

25. Matsumoto T, Nakamura AM, Mori K, Akiyama I, Hirose H, Takahashi Y: Oyster estrogen receptor: cDNA cloning and immunolocalization. Gen Comp Endocrinol 2007, I 5 I:195-201.

26. Bannister R, Beresford N, May D, Routledge EJ, Jobling S, RandWeaver M: Novel estrogen receptor-related Transcripts in Marisa cornuarietis; a freshwater snail with reported sensitivity to estrogenic chemicals. Environmental science \& technology 2007, 4l:2643-2650.

27. Delsuc F, Brinkmann H, Chourrout D, Philippe H: Tunicates and not cephalochordates are the closest living relatives of vertebrates. Nature 2006, 439:965-968.

28. Marletaz F, Holland LZ, Laudet V, Schubert M: Retinoic acid signaling and the evolution of chordates. International journal of biological sciences 2006, 2:38-47.

29. Blair JE, Hedges SB: Molecular phylogeny and divergence times of deuterostome animals. Mol Biol Evol 2005, 22:2275-2284.

30. Schubert M, Escriva $H$, Xavier-Neto J, Laudet V: Amphioxus and tunicates as evolutionary model systems. Trends in ecology \& evolution (Personal edition) 2006, 2 I:269-277.

31. Holland LZ, Gibson-Brown JJ: The Ciona intestinalis genome: when the constraints are off. Bioessays 2003, 25:529-532.

32. Ikuta T, Saiga $H$ : Organization of Hox genes in ascidians: present, past, and future. Dev Dyn 2005, 233:382-389.

33. Dehal P, Satou Y, Campbell RK, Chapman J, Degnan B, De Tomaso A Davidson B, Di Gregorio A, Gelpke M, Goodstein DM, Harafuji N, Hastings KE, Ho I, Hotta K, Huang W, Kawashima T, Lemaire P, Martinez D, Meinertzhagen IA, Necula S, Nonaka M, Putnam N, Rash S Saiga H, Satake M, Terry A, Yamada L, Wang HG, Awazu S, Azumi K, et al:: The draft genome of Ciona intestinalis: insights into chordate and vertebrate origins. Science 2002, 298:2। 57-2 I67.

34. Howard-Ashby M, Materna SC, Brown CT, Chen L, Cameron RA, Davidson $\mathrm{EH}$ : Gene families encoding transcription factors expressed in early development of Strongylocentrotus purpuratus. Developmental biology 2006, 300:90-107.

35. Holland LZ, Albalat R, Azumi K, Benito-Gutiérrez E, Blow MJ, Bronner-Fraser M, Brunet F, Butts T, Candiani S, Dishaw LJ, Ferrier DE, Garcia-Fernàndez J, Gibson-Brown J], Gissi C, Godzik A, Hallböök F, Hirose D, Hosomichi K, Ikuta T, Inoko H, Kasahara M, Kasamatsu J, Kawashima T, Kimura A, Kobayashi M, Kozmik Z, Kubokawa K, Laudet V, Litman GW, Mchardy AC, Meulemans D, Nonaka M, Olinski RP, Pancer Z, Pennacchio LA, Rast JP, Rigoutsos I, Robinson-Rechavi M, Roch G, Saiga H, Sasakura Y, Satake M, Satou Y, Schubert M, Sherwood N, Shiina T, Takatori N, Tello J, Vopalensky P, Wada S, Xu A, Ye Y, Yoshida K, Yoshizaki F, Yu JK, Zhang Q, Zmasek CM, de Jong PJ, Osoegawa K, Putnam NH, Rokhsar DS, Satoh N, Holland PW: The amphioxus genome illuminates vertebrate origins and cephalochordate biology. Genome Res 2008, I 8: I I00-IIII

36. Bardet PL, Schubert M, Horard B, Holland LZ, Laudet V, Holland ND, Vanacker JM: Expression of estrogen-receptor related receptors in amphioxus and zebrafish: implications for the evolution of posterior brain segmentation at the invertebrate-tovertebrate transition. Evolution \& development 2005, 7:223-233.

37. Felsenstein J: Cases in which parsimony or compatibility methods will be positively misleading. Systematic zoology 1978, 27:40I-4I0

38. Shimodaira $H$, Hasegawa M: CONSEL: for assessing the confidence of phylogenetic tree selection. Bioinformatics (Oxford, England) 200I, I 7:I 246-1247.

39. Anisimova M, Gascuel O: Approximate likelihood-ratio test for branches: A fast, accurate, and powerful alternative. Systematic biology 2006, 55:539-552.

40. Guindon S, Gascuel O: A simple, fast, and accurate algorithm to estimate large phylogenies by maximum likelihood. Systematic biology 2003, 52:696-704. 
4l. Lartillot N, Brinkmann H, Philippe H: Suppression of long-branch attraction artefacts in the animal phylogeny using a site-heterogeneous model. $B M C$ evolutionary biology 2007, 7(SuppI I): 54

42. Zhang Z, Burch PE, Cooney AJ, Lanz RB, Pereira FA, Wu J, Gibbs RA Weinstock G, Wheeler DA: Genomic analysis of the nuclear receptor family: new insights into structure, regulation, and evolution from the rat genome. Genome research 2004, 14:580-590.

43. Kuiper GG, Carlsson B, Grandien K, Enmark E, Haggblad J, Nilsson S, Gustafsson JA: Comparison of the ligand binding specificity and transcript tissue distribution of estrogen receptors alpha and beta. Endocrinology 1997, 138:863-870.

44. Gehm BD, McAndrews JM, Chien PY, Jameson JL: Resveratrol, a polyphenolic compound found in grapes and wine, is an agonist for the estrogen receptor. Proceedings of the National Academy of Sciences of the United States of America 1997, 94: I4I38-14I43.

45. Wang LQ: Mammalian phytoestrogens: enterodiol and enterolactone. Journal of chromatography 2002, 777:289-309.

46. Dahlman-Wright $K$, Cavailles V, Fuqua SA, Jordan VC, Katzenellenbogen JA, Korach KS, Maggi A, Muramatsu M, Parker MG, Gustafsson JA: International Union of Pharmacology. LXIV. Estrogen receptors. Pharmacological reviews 2006, 58:773-78I.

47. Wetherill YB, Akingbemi BT, Kanno J, McLachlan JA, Nadal A, Sonnenschein C, Watson CS, Zoeller RT, Belcher SM: In vitro molecular mechanisms of bisphenol A action. Reprod Toxicol 2007, 24:178-198.

48. Yang Z: PAML 4: phylogenetic analysis by maximum likelihood. Mol Biol Evol 2007, 24:1586-159I.

49. Tanenbaum DM, Wang Y, Williams SP, Sigler PB: Crystallographic comparison of the estrogen and progesterone receptor's ligand binding domains. Proceedings of the National Academy of Sciences of the United States of America 1998, 95:5998-6003.

50. Ekena K, Weis KE, Katzenellenbogen JA, Katzenellenbogen BS: Identification of amino acids in the hormone binding domain of the human estrogen receptor important in estrogen binding. The Journal of biological chemistry 1996, 27 1:20053-20059.

5I. Aliau S, Mattras H, Richard E, Bonnafous JC, Borgna JL: Differential interactions of estrogens and antiestrogens at the 17 betahydroxyl or counterpart hydroxyl with histidine $\mathbf{5 2 4}$ of the human estrogen receptor alpha. Biochemistry 2002 4I:7979-7988.

52. Baker ME, Chandsawangbhuwana C: Motif analysis of amphioxus, lamprey and invertebrate estrogen receptors: toward a better understanding of estrogen receptor evolution. Biochem Biophys Res Commun 2008, 37 I:724-728.

53. Brzozowski AM, Pike AC, Dauter Z, Hubbard RE, Bonn T, Engstrom O, Ohman L, Greene GL, Gustafsson JA, Carlquist M: Molecular basis of agonism and antagonism in the oestrogen receptor. Nature 1997, 389:753-758.

54. Pick $H$, Jankevics $H$, Vogel $H$ : Distribution plasticity of the human estrogen receptor alpha in live cells: distinct imaging of consecutively expressed receptors. Journal of molecular biology 2007, 374: $1213-1223$.

55. Shiau AK, Barstad D, Loria PM, Cheng L, Kushner PJ, Agard DA Greene GL: The structural basis of estrogen receptor/coactivator recognition and the antagonism of this interaction by tamoxifen. Cell 1998, 95:927-937.

56. Nolte RT, Wisely GB, Westin S, Cobb JE, Lambert MH, Kurokawa R, Rosenfeld MG, Willson TM, Glass CK, Milburn MV: Ligand binding and co-activator assembly of the peroxisome proliferatoractivated receptor-gamma. Nature 1998, 395:137-| 43.

57. Ohno S: Evolution by gene duplication. Berlin, New York Springer-Verlag;; 1970.

58. Pratt WB, Toft DO: Steroid receptor interactions with heat shock protein and immunophilin chaperones. Endocrine reviews 1997, 18:306-360.

59. Greschik H, Wurtz JM, Sanglier S, Bourguet W, van Dorsselaer A, Moras D, Renaud JP: Structural and functional evidence for ligand-independent transcriptional activation by the estrogenrelated receptor 3. Molecular cell 2002, 9:303-313.

60. Callard GV, Pudney JA, Kendall SL, Reinboth R: In vitro conversion of androgen to estrogen in amphioxus gonadal tissues. Gen Comp Endocrinol 1984, 56:53-58.

61. Castro LF, Santos MM, Reis-Henriques MA: The genomic environment around the Aromatase gene: evolutionary insights. $B M C$ evolutionary biology 2005, 5:43.
62. Baker ME: Co-evolution of steroidogenic and steroid-inactivating enzymes and adrenal and sex steroid receptors. Mol Cell Endocrinol 2004, 21 5:55-62.

63. Bryan MB, Young BA, Close DA, Semeyn J, Robinson TC, Bayer J, Li $W$ : Comparison of synthesis of 15 alpha-hydroxylated steroids in males of four North American lamprey species. Gen Comp Endocrinol 2006, I 46: | 49-156.

64. Paris M, Escriva H, Schubert M, Brunet F, Brtko J, Ciesielski F, Roecklin D, Vivat-Hannah V, Jamin EL, Cravedi J-P, Scanlan TS, Renaud J-P, Holland ND, Laudet V: Amphioxus Postembryonic Development Reveals the Homology of Chordate Metamorphosis. Current Biology 2008, 18:825-830.

65. Losel R, Wehling M: Nongenomic actions of steroid hormones. Nature reviews 2003, 4:46-56.

66. Wehling M, Losel R: Non-genomic steroid hormone effects: membrane or intracellular receptors? J Steroid Biochem Mol Biol 2006, 102:180-183.

67. Losel RM, Falkenstein E, Feuring M, Schultz A, Tillmann HC, RossolHaseroth K, Wehling M: Nongenomic steroid action: controversies, questions, and answers. Physiological reviews 2003, 83:965-1016.

68. Bryan MB, Scott AP, Li W: The sea lamprey (Petromyzon marinus) has a receptor for androstenedione. Biology of reproduction 2007, 77:688-696.

69. Thomas P, Pang Y, Dong J, Groenen P, Kelder J, de Vlieg J, Zhu Y, Tubbs $C$ : Steroid and $\mathbf{G}$ protein binding characteristics of the seatrout and human progestin membrane receptor alpha subtypes and their evolutionary origins. Endocrinology 2007, | 48:705-7|8.

70. Thornton JW: Resurrecting ancient genes: experimental analysis of extinct molecules. Nat Rev Genet 2004, 5:366-375

7I. Bridgham JT, Carroll SM, Thornton JW: Evolution of hormonereceptor complexity by molecular exploitation. Science 2006 , 3 I2(5770):97-10I.

72. Williams PD, Pollock DD, Blackburne BP, Goldstein RA: Assessing the accuracy of ancestral protein reconstruction methods. PLoS computational biology 2006, 2:e69.

73. Volakakis N, Malewicz M, Kadkhodai B, Perlmann T, Benoit G: Characterization of the Nurr I ligand-binding domain co-activator interaction surface. Journal of molecular endocrinology 2006, 37:317-326

74. Iwema T, Billas IM, Beck $Y$, Bonneton F, Nierengarten $\mathrm{H}$, Chaumot $\mathrm{A}$ Richards G, Laudet V, Moras D: Structural and functional characterization of a novel type of ligand-independent RXR-USP receptor. The EMBO journal 2007, 26:3770-3782.

75. Lafont $R$, Mathieu M: Steroids in aquatic invertebrates. Ecotoxicology (London, England) 2007, 16:109-130.

76. Lange IG, Hartel A, Meyer $\mathrm{HH}$ : Evolution of oestrogen functions in vertebrates. J Steroid Biochem Mol Biol 2002, 83:2 19-226.

77. Lu NZ, Wardell SE, Burnstein KL, Defranco D, Fuller PJ, Giguere V, Hochberg RB, McKay L, Renoir JM, Weigel NL, Wilson EM, McDonnell DP, Cidlowski JA: International Union of Pharmacology. LXV. The pharmacology and classification of the nuclear receptor superfamily: glucocorticoid, mineralocorticoid, progesterone, and androgen receptors. Pharmacological reviews 2006, 58:782-797.

78. Olsson PE, Berg AH, von Hofsten J, Grahn B, Hellqvist A, Larsson A, Karlsson J, Modig C, Borg B, Thomas P: Molecular cloning and characterization of a nuclear androgen receptor activated by II-ketotestosterone. Reprod Biol Endocrinol 2005, 3:37.

79. Jaillon O, Aury JM, Brunet F, Petit JL, Stange-Thomann N, Mauceli E, Bouneau L, Fischer C, Ozouf-Costaz C, Bernot A, Nicaud S, Jaffe D, Fisher S, Lutfalla G, Dossat C, Segurens B, Dasilva C, Salanoubat M, Levy M, Boudet N, Castellano S, Anthouard V, Jubin C, Castelli V, Katinka M, Vacherie B, Biemont C, Skalli Z, Cattolico L, Poulain J, et al: Genome duplication in the teleost fish Tetraodon nigroviridis reveals the early vertebrate proto-karyotype. Nature 2004, 43I:946-957.

80. Bryan MB, Scott AP, Li W: Sex steroids and their receptors in lampreys. Steroids 2008, 73: I-12

8I. Markov G, Paris M, Bertrand S, Laudet V: The evolution of the ligand/receptor couple: A long road from comparative endocrinology to comparative genomics. Molecular and Cellular Endocrinology 2008 in press. 
82. Markov G, Lecointre G, Demeneix B, Laudet V: The «street light syndrome», or how protein taxonomy can bias experimental manipulations. Bioessays 2008, 30:349-357.

83. Reschly EJ, Ai N, Ekins S, Welsh WJ, Hagey LR, Hofmann AF, Krasowski MD: Evolution of the bile salt nuclear receptor FXR in vertebrates. Journal of lipid research 2008.

84. Reschly EJ, Ai N, Welsh WJ, Ekins S, Hagey LR, Krasowski MD: Ligand specificity and evolution of liver $\times$ receptors. J Steroid Biochem Mol Biol 2008.

85. Reschly EJ, Bainy AC, Mattos J], Hagey LR, Bahary N, Mada SR, Ou J, Venkataramanan R, Krasowski MD: Functional evolution of the vitamin $\mathbf{D}$ and pregnane $\times$ receptors. $B M C$ evolutionary biology 2007, 7:222.

86. lyer M, Reschly EJ, Krasowski MD: Functional evolution of the pregnane $\times$ receptor. Expert opinion on drug metabolism \& toxicology 2006, 2:381-397.

87. Delaunay F, Pettersson K, Tujague M, Gustafsson JA: Functional differences between the amino-terminal domains of estrogen receptors alpha and beta. Molecular pharmacology 2000, 58:584-590.

88. Penttinen P, Jaehrling J, Damdimopoulos AE, Inzunza J, Lemmen JG Saag P van der, Pettersson K, Gauglitz G, Makela S, Pongratz I: Dietderived polyphenol metabolite enterolactone is a tissue-specific estrogen receptor activator. Endocrinology 2007, I 48:4875-4886.

89. Edgar RC: MUSCLE: multiple sequence alignment with high accuracy and high throughput. Nucleic acids research 2004, 32: $1792-1797$

90. Galtier N, Gouy M, Gautier C: SEAVIEW and PHYLO_WIN. two graphic tools for sequence alignment and molecular phylogeny. Comput Appl Biosci 1996, I 2:543-548.

91. Felsenstein J: Confidence limits on phylogenies: An approach using the bootstrap. Evolution 1985, 39:783-79I.

92. Swofford DL, Waddell PJ, Huelsenbeck JP, Foster PG, Lewis PO, Rogers JS: Bias in phylogenetic estimation and its relevance to the choice between parsimony and likelihood methods. Systematic biology 200I, 50:525-539.

93. Wada H, Escriva H, Zhang S, Laudet V: Conserved RARE localization in amphioxus Hox clusters and implications for Hox code evolution in the vertebrate neural crest. Dev Dyn 2006, 235: |522-|53|.

94. Wang Z, Benoit G, Liu J, Prasad S, Aarnisalo P, Liu X, Xu H, Walker NP, Perlmann T: Structure and function of Nurr I identifies a class of ligand-independent nuclear receptors. Nature 2003, 423:555-560.
Publish with Biomed Central and every scientist can read your work free of charge

"BioMed Central will be the most significant development for disseminating the results of biomedical research in our lifetime. "

Sir Paul Nurse, Cancer Research UK

Your research papers will be:

- available free of charge to the entire biomedical community

- peer reviewed and published immediately upon acceptance

- cited in PubMed and archived on PubMed Central

- yours - you keep the copyright
BioMedcentral 